University of Nebraska - Lincoln

DigitalCommons@University of Nebraska - Lincoln

Ralph Skomski Publications

Research Papers in Physics and Astronomy

2014

\title{
Practical Aspects of Modern and Future Permanent Magnets
}

R.W. McCallum

Ames Laboratory, lowa State University, Ames, lowa

L. H. Lewis

Northeastern University

Ralph Skomski

University of Nebraska-Lincoln, rskomski2@unl.edu

M. J. Kramer

US Department of Energy, lowa State University

I. E. Anderson

US Department of Energy, lowa State University

Follow this and additional works at: https://digitalcommons.unl.edu/physicsskomski

Part of the Engineering Physics Commons, and the Metallurgy Commons

McCallum, R.W.; Lewis, L. H.; Skomski, Ralph; Kramer, M. J.; and Anderson, I. E., "Practical Aspects of Modern and Future Permanent Magnets" (2014). Ralph Skomski Publications. 98.

https://digitalcommons.unl.edu/physicsskomski/98

This Article is brought to you for free and open access by the Research Papers in Physics and Astronomy at DigitalCommons@University of Nebraska - Lincoln. It has been accepted for inclusion in Ralph Skomski Publications by an authorized administrator of DigitalCommons@University of Nebraska - Lincoln. 
Annu. Rev. Mater. Res. 2014. 44:451-77

First published online as a Review in Advance on April 10, 2014

The Annual Review of Materials Research is online at matsci.annualreviews.org

This article's doi:

10.1146/annurev-matsci-070813-113457

Copyright (c) 2014 by Annual Reviews. All rights reserved

U.S. government works are not subject to copyright.

\section{Practical Aspects of Modern and Future Permanent Magnets}

\author{
R.W. McCallum, ${ }^{1,2}$ L.H. Lewis, ${ }^{3}$ R. Skomski, ${ }^{4}$ \\ M.J. Kramer, ${ }^{1,2}$ and I.E. Anderson ${ }^{1,2}$
}

\footnotetext{
${ }^{1}$ The Ames Laboratory, US Department of Energy, Iowa State University, Ames, Iowa 50011; email: mccallum@ameslab.gov, mjkramer@ameslab.gov, andersoni@ameslab.gov

${ }^{2}$ Department of Materials Science and Engineering, Iowa State University, Ames, Iowa 50011

${ }^{3}$ Department of Chemical Engineering, Northeastern University, Boston, Massachusetts 02115; email: lhlewis@neu.edu

${ }^{4}$ Department of Physics and Astronomy and Nebraska Center for Materials and Nanoscience, University of Nebraska, Lincoln, Nebraska 68588; email: rskomski2@unl.edu
}

\section{Keywords}

alnico, ferrite, rare earth magnets, energy product, magnetic anisotropy

\begin{abstract}
The mandate to reduce greenhouse gases will require highly efficient electric machines for both power generation and traction motor applications. Although permanent magnet electric machines utilizing $\mathrm{Nd}_{2} \mathrm{Fe}_{14} \mathrm{~B}$-based magnets provide obvious power-to-weight advantages over induction machines, the limited availability and high price of the rare earth (RE) metals make these machines less favorable. Of particular concern is the cost and supply criticality of Dy, a key $\mathrm{RE}$ element that is required to improve the high-temperature performance of Nd-based magnetic alloys for use in generators and traction motors. Alternatives to RE-based alloys do exist, but they currently lack the energy density necessary to replace Nd-based magnets. Many of these compounds have been known for decades, but serious interest in their development waned once compounds based on RE elements were discovered. In this review, intrinsic and extrinsic materials factors that impact the optimization of both existing and potential future permanent magnets for energy applications are examined in light of new insights gained from renewed examination.
\end{abstract}




\section{INTRODUCTION}

\section{Permanent Magnet Impact}

Permanent magnets create a magnetic field $\mathbf{H}$ in free space without the continuous expenditure of electric or other forms of energy and play an essential role in modern society. Despite the hundreds of magnets in or on the average house, car, and teenager, if you asked typical consumers to name their possessions that contain magnets, they would probably give you a very short list. The diverse applications of permanent magnets create a demand for a large variety of materials based on the application requirements, including the strength of the magnet for a given size; the ability of the magnet to maintain its field in the presence of a reverse field, high temperatures, and hostile environments; and, of course, its cost. Bonded oxide magnets, made of inexpensive strontium ferrite $\mathrm{SrFe}_{12} \mathrm{O}_{19}$ or $\mathrm{SrO}-6 \mathrm{Fe}_{2} \mathrm{O}_{3}$, pitch advertisements on your refrigerator and seal the refrigerator door. Sintered ferrites in the magnetron assist in generating microwaves in your microwave oven. Alnico magnets-which are composed mostly of $\mathrm{Fe}, \mathrm{Al}, \mathrm{Ni}$, and $\mathrm{Co}$, with minor additions of $\mathrm{Cu}$, $\mathrm{Ti}$, and/or $\mathrm{Si}$-are in the circuit switch sensors of your burglar alarm. The more expensive bonded $\mathrm{Nd}-\mathrm{Fe}-\mathrm{B}$ or "neo" magnets $\left(\mathrm{Nd}_{2} \mathrm{Fe}_{14} \mathrm{~B}\right)$ spin your CDs and DVDs, and sintered neo magnets move the read/write head across your computer hard disk, recording and retrieving data.

Large volumes of permanent magnets are found in hybrid and electric vehicles, direct-drive wind turbines, and many energy-efficient appliances. These magnets are vitally important to military applications, as they add functionality to jet fighter engines and electronic countermeasure, missile, and satellite communication systems. Here we present an overview of the past, present, and possible future magnetic alloys and compounds used in permanent magnet-based electric machines in light of current market and supply pressures on constituent rare earth (RE) elements. With the ever-widening and intensive uses for magnets, researchers must now consider the criticality of the constituent elements as a major factor in the development of permanent magnets. Criticality evaluates the technological importance of a material in terms of the probability of a disruption of supply based on the number of sources, long-term abundance, availability of substitutes, and impact of these factors on cost and sustainability. We also discuss prospects for replacing RE-based alloys with more abundant and less strategically important elements.

\section{Historical Perspective}

Permanent magnets were arguably one of the earliest functional materials. Lodestones, composed mainly of magnetite, were known in ancient times (1). Sir William Gilbert, a physician and scientist in the court of Elizabeth I, first reported on the magnetic properties of ferrous materials in the late 1500 s (2). The discovery of electromagnetism in the early nineteenth century by André-Marie Ampère, combined with the formalism of Maxwell's equations, set the stage for linking mechanical work to electromagnetism. By the end of the 1800 s, the requirements to realize simple electric motors and generators were well described $(3,4)$.

\section{Rare Earth Supermagnets: Supply and Uses}

By the 1990s, RE-based supermagnets were both cheap and plentiful. Although the demand for RE-based magnets for disk drives and consumer electronics was increasing steadily, supplies of RE metals easily met that demand. However, toward the advent of the twenty-first century, growing concerns about air quality, carbon emissions, and the rising cost of petroleum accelerated the global search for alternatives to traditional fossil fuel-based energy sources and for more efficient 
utilization of energy. This situation ignited a rapid escalation of demand for hybrid electric cars and for wind-powered electric generators; the former rely heavily on neo magnets, and the latter are made more reliable through the extensive use of these magnets. This increased demand was accompanied by geopolitical pressures with regard to RE production and supply because of the concentration over the past few decades of RE production in a single country: China.

In 2009, China announced it would begin to curtail its export of the RE elements Eu, Tb, and Dy $(5,6)$. The initial announcement of export quotas sent prices soaring and resulted in the European Union (EU), Japan, and the United States filing complaints against these quotas, citing unfair trading practices, with the World Trade Organization in 2012 (7). This move by China also spurred the EU, Japan, and the United States to take a critical look at their near-total dependence on a single supplier for these critical elements (8-10). As of 2014, with the slow recovery of the worldwide economy, the overall geopolitical landscape of RE supply and demand remains fluid (11).

Regardless of the geopolitical environment surrounding the supply and refinement of RE elements, increase in demand, driven primarily by increased use of electric machines, will be a major factor in the availability of RE elements in the near future. The availability, and hence the cost, of these elements is not uniform. For example, the higher-temperature performance requirement of generators and traction motors requires an adjustment to the Nd-based permanent magnet alloy composition to improve its high-temperature resistance to demagnetization, quantified by the permanent loss of its magnetic field $\mathbf{B}$ from an opposing magnetic field $\mathbf{H}$. This modification allows the generator or motor to maintain its integrity during operation.

This compositional adjustment is accomplished largely with the addition of heavy RE elements, primarily Dy, whose proven global resources are inadequate to meet this demand (12). Although additions of $\mathrm{Dy}$ to $\mathrm{RE}_{2} \mathrm{Fe}_{14} \mathrm{~B}$-based magnets reduce the resulting magnets' field strength as measured by the remanence $B_{\mathrm{r}}$, Dy-when partially substituted into the crystal structure for $\mathrm{Nd}$ - moderately increases the Curie temperature $T_{\mathrm{c}}$, which is desirable for high-temperature performance. Most significantly, Dy significantly increases the resistance to demagnetization-the intrinsic coercivity $H_{\mathrm{cJ}}$-at elevated temperatures up to $\sim 200^{\circ} \mathrm{C}$ by increasing the magnetocrystalline anisotropy field $H_{\mathrm{A}}$. These modifications to the magnetic properties translate to significant improvements in the elevated-temperature performance of the magnet. The price of this essential RE element fluctuated from near $\$ 100 / \mathrm{kg}$ in early 2009 to as high as $\$ 3,400 / \mathrm{kg}$ in August 2011 and remained near $\$ 625 / \mathrm{kg}$ as of March $2014(13,14)$. The amount of Dy added to conventionally processed Nd-based magnets can be as high as $12 \mathrm{wt} \%$ for more demanding electric machine applications operating at $220^{\circ} \mathrm{C}$ (Figure 1) (15). This level of Dy use is simply not sustainable at this price.

Global research efforts are currently under way to reduce the amount of Dy in Nd-based magnets required for high-temperature device operation (16). Additionally, new electric machine designs that employ reduced quantities of permanent magnets are under investigation, but all have performance shortcomings. For example, the permanent magnet synchronous generators in commercial wind turbines compete with induction generators that contain no permanent magnets. These induction generators require high-ratio gearboxes subject to expensive regular maintenance cycles. Recently, hybrid drive generators have been developed that use both permanent magnets and inductance, allowing the use of a simple two-stage gearbox with lower maintenance requirements than the high-ratio gearboxes; these generators require only one-third of the weight of permanent magnets compared with permanent magnet (PM) direct-drive generators. Thus, whereas gearbox failure, a major problem for induction generators (17), is mitigated by the new hybrid designs, it is eliminated entirely in the permanent magnet synchronous generators. The development of superconducting generators to power wind turbines is currently under investigation for larger systems $(\geq 10 \mathrm{MW})$ and may further change the landscape for RE-based permanent magnets (18). 


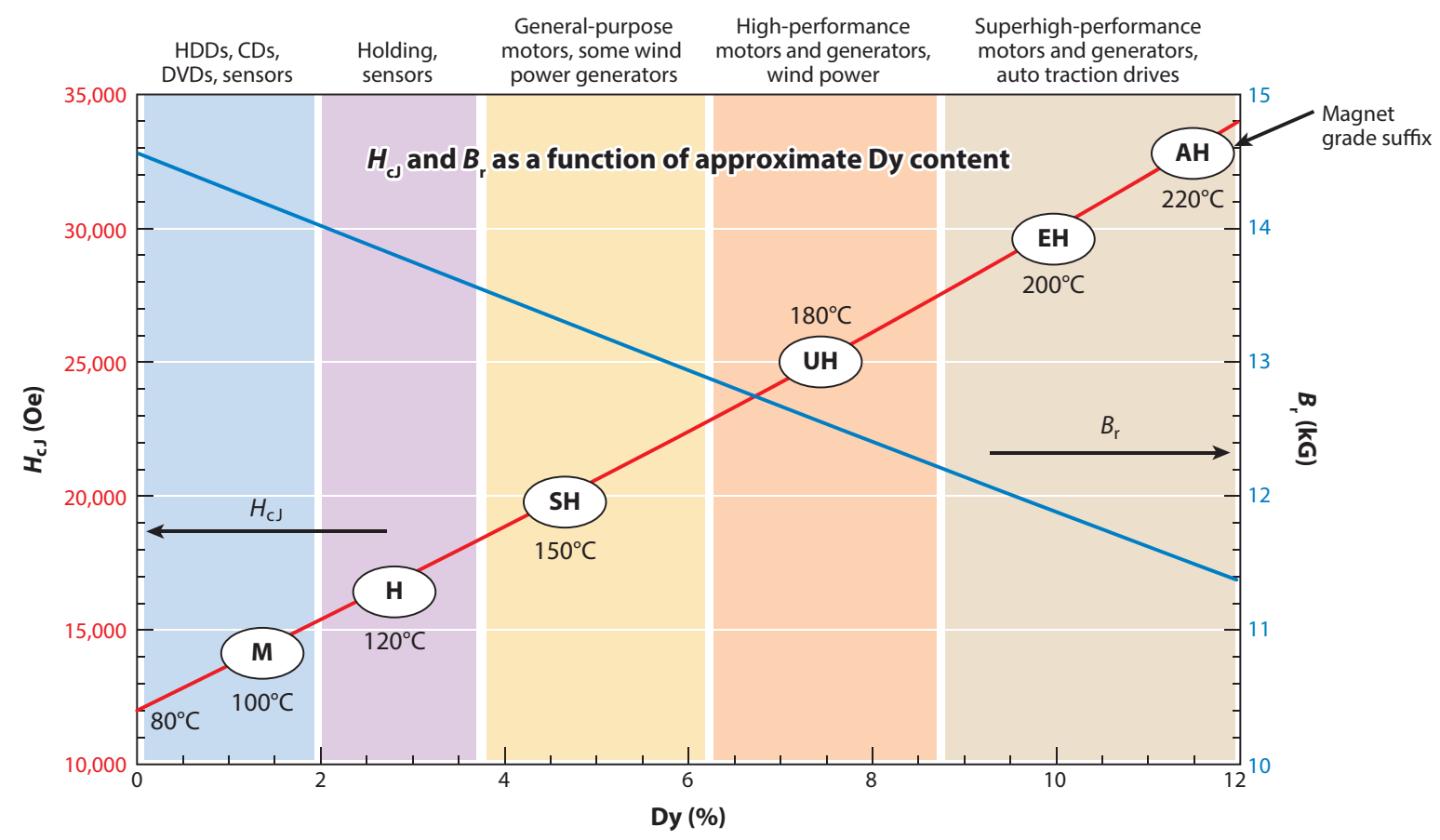

Figure 1

The intrinsic coercivity $\left(H_{\mathrm{cJ}}\right)$ and remanence, or induction $\left(B_{\mathrm{r}}\right)$, as a function of alloy Dy content in weight percent for commercial $\mathrm{NdFeB}$-based magnets. The ovals contain the grade designations $\mathrm{M}, \mathrm{H}, \mathrm{SH}, \mathrm{UH}, \mathrm{EH}$, and AH based on the maximum operating temperature noted for that grade. Typical uses for each grade are shown along the top columns. Data supplied by Arnold Magnetic Technologies, http://www.arnoldmagnetics.com.

Automotive traction drive motors have even more demanding magnet size and weight considerations than those of wind turbines, especially in hybrid vehicles in which there is limited space for the electric motor between the internal combustion engine and the wheel wells. Although induction motors remain an option for all-electric vehicles, considerations of superior power conversion efficiency, desired high torque over a wide rpm range, and a favorable massto-power ratio clearly favor the use of a high-performance, permanent magnet-based motor for many applications (19). However, the advantages of permanent magnet-based machines disappear if lower-energy-product magnets, such as current non-RE permanent magnets, are used. Even though most non-RE permanent magnetic materials developed prior to the invention of $\mathrm{RE}$ permanent magnets are still commercially produced, the development of these older materials has been neglected since the end of the 1970s. We discuss a few of the more promising non-RE-containing systems with the potential to replace RE-based permanent magnet alloys in electric machines. Additionally, we articulate challenges to improving the magnetic and structural properties of these select systems to meet the demanding and escalating performance criteria for permanent magnet machines.

\section{MAGNETIC METRICS AND PHENOMENA}

The properties and performance of a permanent magnet depend both on the characteristics of the base compound (i.e., intrinsic properties) and on the attributes of the microstructure (i.e., extrinsic 


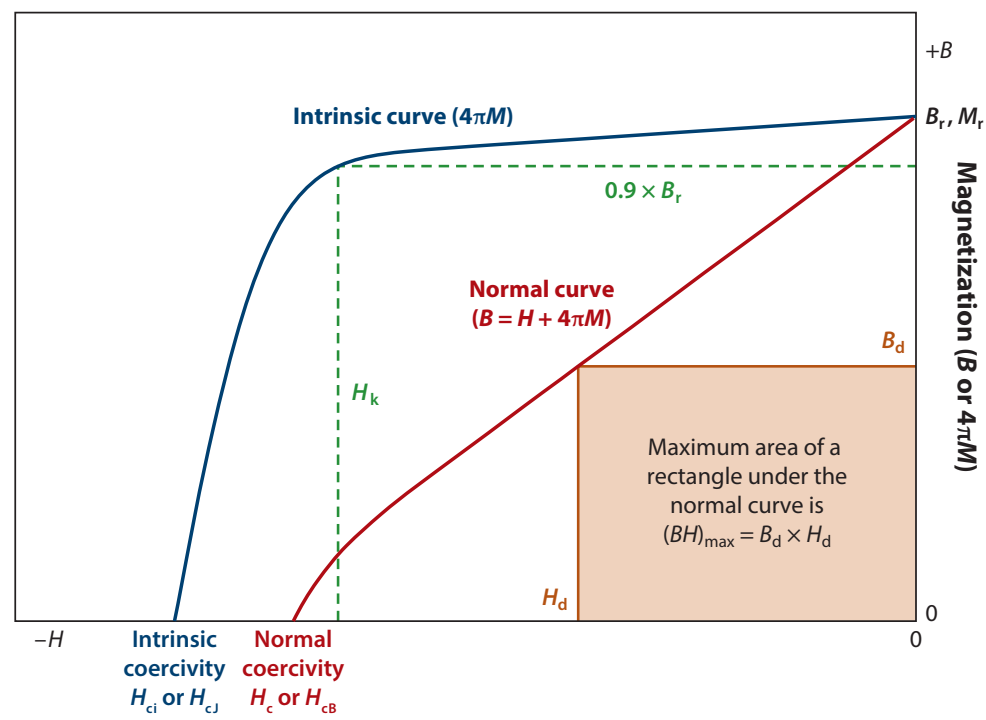

Field $(H)$

Figure 2

The second-quadrant demagnetization curves for a permanent magnet obtained in a decreasing field after saturation in the $+H$ direction.

properties). In this section, after an introductory overview of terminology and phenomena, we compare and contrast the intrinsic and extrinsic properties of several classes of technologically relevant magnetic materials.

\section{Terminology and Phenomena}

Technologically, the creation of a magnetic field $\mathbf{H}$ in free space without continuous expenditure of electric or other forms of energy is highly desirable (Figure 2). The field created by a permanent magnet is proportional to the magnet's magnetization $\boldsymbol{M}$, which is an intrinsic property of a given substance. The net magnetization $M_{\mathrm{at}}$ is an average of atomic magnetization contributions, such that $M_{\mathrm{at}}=m_{\mathrm{at}} / V_{\mathrm{at}}$, where $m_{\mathrm{at}}$ is the atomic moment-often measured in units of the Bohr magneton, $\mu_{\mathrm{B}}=9.274 \times 10^{-24} \mathrm{~J} / \mathrm{T}$-and $V_{\text {at }}$ is the crystal volume per atom. The Bohr magneton is a useful metric that describes the magnetic moment of a free electron. For large values of an externally applied $\mathbf{H}$, the atomic moments are forced to align with $\mathbf{H}$, and the maximum value of the field-dependent magnetization $\boldsymbol{M}(H)$ —defined as $M_{\mathrm{s}}$, the saturation or spontaneous magnetization-is achieved. Physically, the main source of $M_{\mathrm{at}}$ is the spin angular momenta $\mathbf{S}$, that is, the spin moment of the electrons in the unfilled electron shells of transition metal ( $3 d$, $4 d, 5 d$ ) or lanthanide $(4 f)$ atoms. However, the orbital angular momentum (orbital moment) $\mathbf{L}$ of these electrons is also important in some magnetic compounds (20). In the SI system, both $\mathbf{H}$ and $\boldsymbol{M}$ are measured in $\mathrm{A} / \mathrm{m}$, although it is often more convenient to consider the quantities $\mu_{\mathrm{o}} \boldsymbol{H}$ and $J=\mu_{\mathrm{o}} \boldsymbol{M}$, both measured in T, with $\mu_{\mathrm{o}}$ representing the permittivity of free space $\left(\mu_{\mathrm{o}}=4 \pi \times\right.$ $\left.10^{-7} \mathrm{H} / \mathrm{m}\right)$. In the cgs system, these units are $\mathrm{Oe}=10^{-4} \mathrm{~T}(\boldsymbol{H})$ and $\mathrm{emu} / \mathrm{cm}^{3}=\mathrm{kA} / \mathrm{m}(\boldsymbol{M})$.

The magnetization is field-dependent because the external field $\mathbf{H}$ aligns or rotates the atomic magnetic moments, usually without changing the magnitude of the moments themselves. Furthermore, different volume elements within a macroscopic magnet interact with each other 
magnetostatically via the dipole-dipole coupling of the local magnetic moments; this interaction provides a low-energy state and favors spatial magnetization distributions $\boldsymbol{M}(\mathbf{r})$, where $\mathbf{r}$ is a position vector, with low net magnetization. For permanent magnet applications, it is desirable to stabilize the local magnetization direction to provide a uniaxial magnetic state; this stabilization is achieved by developing magnetic anisotropy, a single preferred direction of the magnetization with respect to the physical body of the magnet. The most important source of magnetic anisotropy is the magnetocrystalline anisotropy. Magnetocrystalline anisotropy dictates how the magnetic energy depends on the magnetization directions relative to the crystal axes of the magnetic compound and inhibits the collapse or switching of the magnetization in a reverse (or negative) magnetic field. It is characterized by the anisotropy constants that have units of energy density $\left(\mathrm{MJ} / \mathrm{m}^{3}=10^{7} \mathrm{erg} / \mathrm{cm}^{3}\right)$. The first anisotropy constant, $K_{1}$, or simple anisotropy is the most important constant and is quantified in terms of an anisotropy field $H_{\mathrm{A}}=2 K_{1} / M_{\mathrm{s}}$ that specifies the magnetic field required to rotate the magnetization direction from the low-energy magnetic direction (easy axis) to the high-energy direction (hard axis) of a given crystal structure. Unfortunately, the inverse dependence of $H_{\mathrm{A}}$ on $M_{\mathrm{s}}$ prevents the simultaneous maximization of both $H_{\mathrm{A}}$ and $M_{\mathrm{s}}$ in a given single-phase system. Technologically relevant magnet alloys have noncubic crystal structures (hexagonal, tetrahedral, or rhombohedral) $(21,22)$. The associated anisotropic electrostatic crystal field inherent in these lower-symmetry structures modifies the orbital motion of the electrons and affects the overall spin system via spin-orbit coupling (23). Because spin-orbit coupling is a relativistic mechanism, the magnetocrystalline anisotropy is large for heavy elements (i.e., those with a high atomic number $Z$ ) such as the RE elements. Another important form of magnetic anisotropy is shape anisotropy, a purely geometric effect that can become quite appreciable in magnetic materials with ellipsoidal or acicular shapes on a sufficiently fine scale.

In a sufficiently large reverse field, with a thus far unachieved upper limit determined by $H_{\mathrm{A}}$, the magnetization of a magnet will start to reverse. The reverse field where the magnetization vanishes, $\boldsymbol{M}(H)=0$, defines the coercivity $H_{\mathrm{c}}$ (Figure 2). The maximum magnetostatic energy in free space, normalized to the magnet volume, describes the work that can be performed by a permanent magnet. It is quantified by the maximum energy product $(\boldsymbol{B H})_{\max }$. This parameter can be determined from the $\boldsymbol{M}(H)$ hysteresis loop or, more precisely, from the $\mathbf{B}(\boldsymbol{H})$ hysteresis loop, where $\mathbf{B}=\mu_{\mathrm{o}}(\mathbf{M}+\mathbf{H})$ and $\mathbf{B}(\mathbf{H})=\mu_{\mathrm{o}}[\mathbf{M}(H)+\mathbf{H}] .(B H)_{\max }$ is equal to the magnitude of the maximum of the product $|B \cdot H|$ as $\mathbf{H}$ is varied (Figure 2) (22). As an energy density, it is measured in $\mathrm{kJ} / \mathrm{m}^{3}=4 \pi / 100$ MGOe (MegaGauss-Oersted).

\section{Intrinsic Magnetic Properties}

Intrinsic magnetic properties depend on the crystal structure and chemical composition of the base compound. In particular, the crystal structure of the main families of RE-based magnets consists of two interpenetrating atomic sublattices, one composed of transition metal (TM) components and the other composed of RE components. Figure 3 shows the crystal structure of the prototypical compound $\mathrm{Nd}_{2} \mathrm{Fe}_{14} \mathrm{~B}$, in which $\mathrm{TM}(\mathrm{Fe})$ nets providing high magnetization are layered with RE elements $(\mathrm{Nd})$. The $M_{\mathrm{s}}$ and $T_{\mathrm{c}}$ of most magnets are determined largely by the TM $(3 d)$ sublattice. Some atoms-particularly RE atoms with high $Z$-found in RE-based permanent magnets also carry a magnetic moment, but their contribution to the overall magnetization is diluted by the larger atomic volume of high- $Z$ elements. The magnetization of the TM component in the RE magnet lattice is determined largely by the total spin angular momentum vector $(\mathbf{S})$ of the unpaired electrons; the TM orbital moment of those electrons $\left(\boldsymbol{L}_{\mathrm{TM}}\right)$ is typically quenched by the lattice in these compounds $\left(\boldsymbol{L}_{\mathrm{TM}}=0\right)$. RE magnets owe their superior performance to the spatial localization of $4 f$ electrons/moments within the $\mathrm{RE}$ atoms. As these 


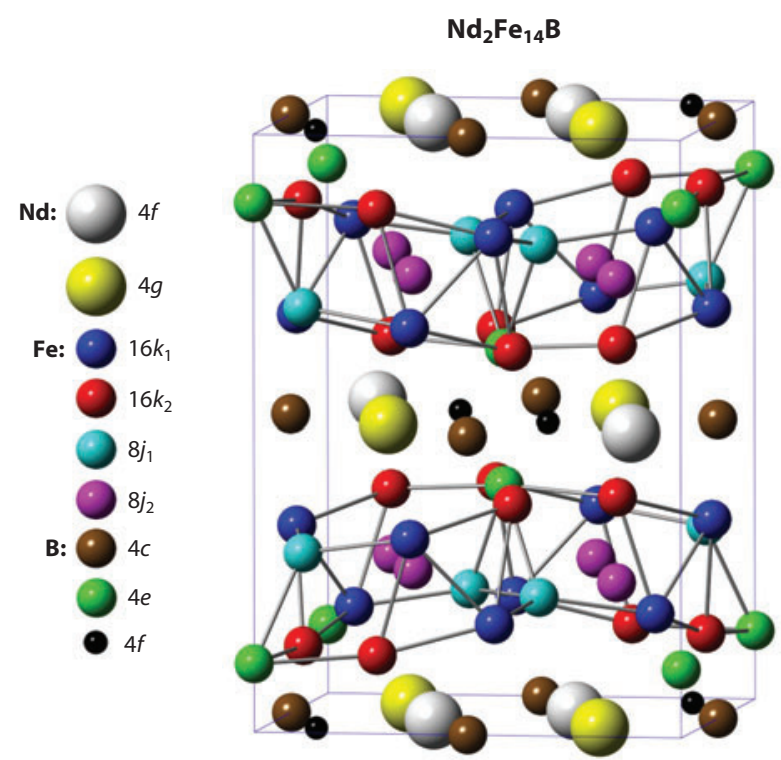

Figure 3

The crystal structure of $\mathrm{Nd}_{2} \mathrm{Fe}_{14} \mathrm{~B}$ showing high-moment Fe layers separated by high-anisotropy, Nd-containing layers.

inner-shell electrons do not interact with the lattice-bonding electrons, the total RE angular momentum remains unquenched $\left(\boldsymbol{L}_{\mathrm{RE}} \neq 0\right)$. Consequently, the very strong spin-orbit coupling ensures that the lanthanide $4 f$ electron charge clouds, described by Stevens coefficients, are rigidly coupled to the $d$ electron spins of the TM component (24). In this manner, the corresponding RE magnet anisotropy energy is equal to the electrostatic interaction energy difference as a function of orientation between the RE ions and the anisotropic crystal field.

By contrast, the magnetocrystalline anisotropy of permanent magnets that do not contain RE elements, referred to here as TM magnets, reflects the interplay between the crystal-field and spin-orbit interactions of the $d$ electrons. In a TM magnet, the physical origin of magnetocrystalline anisotropy is derived from the electrostatic energy of the $3 d$ electron cloud. This crystalfield or electrostatic energy depends on the electron cloud's orientation relative to that of the bonds that define the crystal axes. The spin-orbit coupling in TM-based magnets is derived from $3 d$ electrons that execute a circular motion with an axis of rotation parallel to the electron spin direction in space. The corresponding $3 d$ electron cloud may be oblate or prolate, depending on the involved orbitals, but it is the spin-orbit coupling phenomenon that links this cloud's axis of revolution to the spin direction. Figure 4 illustrates the basic physical mechanism underlying the magnetocrystalline anisotropy in chemically ordered magnets such as $\mathrm{L} 1_{0}$-type ( $\tau$-phase) $\mathrm{MnAl}$, in which the magnetocrystalline anisotropy originates from the Mn electrons.

In Figure $4 a$, the Mn charge clouds are predominantly located in the Mn planes, whereas in Figure $4 \boldsymbol{b}$, these charge clouds reach deep into the $\mathrm{Al}$ layers. The crystal field in the $\mathrm{L} 1_{0}$-ordered magnets results from the different electronic structures of the chemically distinct atomic layers that constitute this crystal. Tetragonally strained cubic magnets yield conceptually similar but much weaker crystal fields (20), which lead to magnetoelastic anisotropy. In turn, pseudocubic $\mathrm{L}_{0}$ magnets with axial ratios $a \sim b \sim c$ generally exhibit large anisotropies associated with the chemical constituents in the structure. 
a

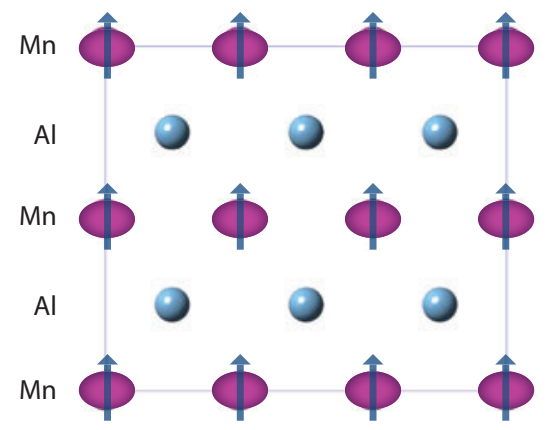

b

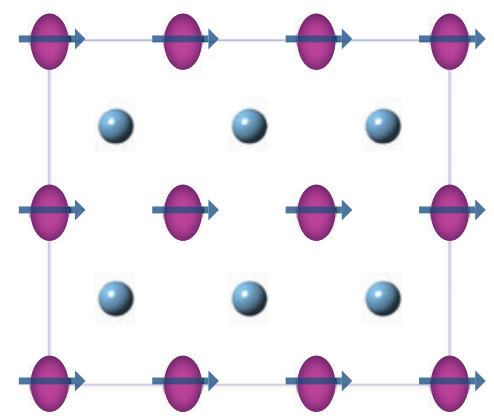

Figure 4

Origin of magnetocrystalline anisotropy in a typical noncubic, transition-metal permanent magnet, using $\mathrm{L} 1{ }_{0}$-ordered $\mathrm{MnAl}$ as an example. (a) Spins parallel to the $c$-axis. (b) Spins parallel to the $b$-axis. The electrostatic (and hopping) energy difference between panels $a$ and $b$ is equal to the anisotropy energy.

Although it provides a qualitatively correct explanation of the magnetocrystalline anisotropy origins in TM-based magnets, the above description is insufficiently nuanced. First, the spin-orbit coupling of $3 d$ TM atoms is much smaller than the crystal-field and/or hybridization energy. Therefore, spin-orbit coupling scarcely perturbs the energy of the system, and the pronounced charge-density difference between the configurations represented in Figure $4 a$ and Figure $4 b$ is exaggerated. As the composition of the magnetic compound moves from being $3 d$-rich to incorporating the $4 d$ and $5 d$ elements, the corresponding spin-orbit coupling constants of the unpaired electrons increase by as much as an order of magnitude, with parallel increases in the spin-orbit-coupling contribution to magnetocrystalline anisotropy. Second, the $3 d, 4 d$, or $5 d$ electrons in the partially filled shells of TM atoms have itinerant character, unlike the localized $4 f$-orbitals shown in Figure 4. Thus, calculations of the magnetocrystalline anisotropy energies in these materials require first-principle computational approaches. The largest contributions to the $d$-electron-based magnetocrystalline anisotropy stem from the electronic states immediately above and below the Fermi level, and both the position of the Fermi level and the character of its nearby states depend strongly on crystal structure and chemistry. Turning the magnetization direction by $90^{\circ}$, e.g., from the $c$-axis into the $a$ - $b$-plane, affects the spin-orbit coupling. The corresponding energy-level changes are usually small and can have either sign, depending on the wave vector of the involved electrons, but they have a disproportionally strong effect on the subtle energy balance near the Fermi level and on the net anisotropy. Reliable anisotropy calculations for itinerant magnets, including metallic $\mathrm{MnAl}$, require the use of numerical methods including density functional theory (DFT) calculations (25). In most cases, the anisotropy per atom can be approximately assigned to individual atoms, a concept known as single-ion anisotropy. However, by absolute standards, single-ion anisotropy is very weak-roughly on the order of $0.1 \mathrm{meV}$ or $1 \mathrm{~K}$-such that the parallel spin configuration shown in Figure 4 is very easily destroyed by thermal fluctuations, even at temperatures $<4 \mathrm{~K}$. However, when the $d$-electron spins are coupled through the exchange interaction and are magnetically ordered as a result, strong collective magnetocrystalline anisotropies can be realized by adding the single-ion contributions.

A survey of the intrinsic magnetocrystalline anisotropy values of the $3 d$ (TM)-type magnets informs the search for promising TM-based magnets. In spite of the small single-ion anisotropy, the spin-orbit coupling mechanism in the $3 d$ magnetic materials systems described above yields anisotropies $\left(K_{1}\right)$ that are $\sim 20 \%$ of the anisotropy of, for example, the RE-containing magnetic 
compound $\operatorname{Pr}_{2} \mathrm{Fe}_{14} \mathrm{~B}$, which has a $K_{1}$ of $5 \mathrm{MJ} \mathrm{m}^{-3}$ over a broad temperature range. Comparable values of $K_{1}$ are observed in $\mathrm{L}_{1}$-type alloys containing $4 d$ and $5 d$ elements, such as $\operatorname{CoPt}\left(4.9 \mathrm{MJ} \mathrm{m}^{-3}\right)$, $\mathrm{FePt}\left(6.6 \mathrm{MJ} \mathrm{m}^{-3}\right)$, and $\mathrm{FePd}\left(1.8 \mathrm{MJ} \mathrm{m}^{-3}\right)$. These large anisotropy values are not surprising, as the $4 d$ and $5 d$ electrons of $\mathrm{Pd}$ and $\mathrm{Pt}$ participate in strong spin-orbit coupling to donate a large spin polarization, which is on the order of $0.5 \mu_{\mathrm{B}}$ per $4 d / 5 d$ atom. As described above, the anisotropy of the $\mathrm{L} 1_{0}$-ordered $\mathrm{MnAl}\left(1.7 \mathrm{MJ} \mathrm{m}^{-3}\right)$ phase is ascribed to the $\mathrm{Mn}$ sublattice. In $\mathrm{L}_{0}$-type $\mathrm{FeNi}$, also known as tetrataenite (discussed in detail below), the anisotropy magnitude of $0.32 \mathrm{MJ} \mathrm{m}^{-3}$ stems from the participating $\mathrm{Fe}$ and $\mathrm{Ni} 3 d$ electrons and may be extrapolated to a theoretically predicted, zero-temperature magnetocrystalline anisotropy of $0.6 \mathrm{MJ} \mathrm{m}^{-3}$. MnBi, which crystalizes in the hexagonal NiAs structure, is a very complex material with strongly temperature-dependent anisotropy on the order of $1.2 \mathrm{MJ} \mathrm{m}^{-3}$ near room temperature. Although the Bi component has a magnetic moment of only $-0.08 \mu_{\mathrm{B}}$ per $\mathrm{Bi}$ atom, as a heavy element it exhibits strong spin-orbit coupling and therefore produces pronounced anisotropy. Two particular features of $\mathrm{MnBi}$ are the involvement of $\mathrm{Bi} 6 p$ electrons, in addition to the $\mathrm{Mn} 3 d$ electrons, in bonding and the large spinorbit coupling of the $5 d$ electrons of $\mathrm{Bi}$, which results in high magnetocrystalline anisotropy (26).

\section{Extrinsic Properties}

Whereas the $M_{\mathrm{s}}$ and $K_{1}$ parameters are intrinsic properties of the magnetic compound or alloy composing the magnet, $M(H)$ and $H_{\mathrm{c}}$ are extrinsic properties that depend on the materials' microstructure and, to a lesser degree, the bulk shape of the magnet. $M(H)$ depends highly on the crystallographic alignment or texture of the grains that comprise the magnet. Highly aligned grains foster an $M(H)$ response that is largely independent of $\mathbf{H}$; as the field is reduced from the saturation field, regions of uniform reverse magnetic polarization, known as magnetic domains, form. At the coercive field $H_{\text {ci }}$, a number of reverse domains separated by the domain walls are formed such that the vector magnetization of the magnetic body averages to zero. This process occurs even in a compound with large magnetocrystalline anisotropy, such as $\mathrm{Nd}_{2} \mathrm{Fe}_{14} \mathrm{~B}$. In isotropic magnets that lack crystallographic texture, the magnetization of each individual grain relaxes to its own anisotropy axis as the applied magnetic field is reduced to zero. This process results in a large field dependence of $M(H)$ prior to the formation of reverse domains and drastically reduces $(B H)_{\max }$.

The formation of reversed magnetic domains under the influence of a reversed field depends highly on the microstructure of the magnet, including the grain size, grain shape, and magnetic coupling between the grains. By carefully controlling the microstructure, the formation of reverse domains can be hindered, increasing $H_{\mathrm{c}}$. In practice, many features in a real magnet microstructure limit the nucleation of reverse domains or pin domain walls once the reversed domains nucleate, thereby allowing the actual critical grain size to exceed the calculated single-domain grain size. The creation of grains with highly irregular grain boundaries containing sharp or protuberant asperities must be avoided in the magnet microstructure because such irregularities provide lower-energy nucleation sites for domain reversal, reducing $H_{\mathrm{c}}$. Thus, a magnet microstructure composed of very fine, uniform, and crystallographically aligned grains is required to maximize $M(H)$ and hence, to achieve a large $(B H)_{\max }$.

\section{Permanent Magnet Design Considerations}

The design of a permanent magnet requires balancing intrinsic and extrinsic magnetic effects; mechanical, thermal, and chemical aspects must also be considered. An illustrative example of the challenges inherent in optimizing technical magnetic behavior is found in the alnico family of magnets. The alnicos—which had their heyday in the 1940s and 1950s and are discussed in more 
detail below-possess an overall alloy composition of Al-Ni-Co-Fe that spinodally phase separates, upon appropriate processing, into highly ferromagnetic Fe-Co nanoscaled precipitates separated by a nonmagnetic, NiAl-rich, intermetallic phase matrix (27-30). Although the Fe-Co phase can have the highest magnetization of any known material (2.43 $\mathrm{T}$ at the $\mathrm{Fe}_{65} \mathrm{Co}_{35}$ composition), its cubic crystal structure has four directions of easy magnetization, along the [100] axes, with very low magnetocrystalline anisotropy. Alnico magnets derive their magnetic anisotropy, and hence their coercivity, from the shape of the magnetic Fe-Co phase precipitates in this intrinsic nanocomposite. Despite appreciable magnetic anisotropy, the alnico magnetization is reduced to $\sim 60 \%$ of the theoretical value for Fe-Co because of the unavoidable presence of the nonmagnetic matrix phase that separates the distinct magnetic precipitates.

One alternative to relying on shape anisotropy to realize coercivity is to use selected noncubic, intermetallic compounds with the potential for significant uniaxial magnetocrystalline anisotropy and with a high percentage of moment-bearing TM elements (typically $\mathrm{Mn}, \mathrm{Cr}, \mathrm{Fe}$, and $\mathrm{Ni}$ ). Unfortunately, the magnetic moments of the $3 d$ TM elements depend highly on their chemical environment, the TM-TM interatomic distance, and the quantum-mechanical exchange interaction that determines the magnetic ordering temperature $\left(T_{\mathrm{c}}\right)$. Each TM element has an optimum atomic structure and interatomic spacing for good intrinsic magnetic properties. Closer spacing sometimes promotes antiferromagnetic alignment, whereas larger spacing can reduce the exchange interaction, resulting in lower $T_{\mathrm{c}}$ along with reduced magnetization from enhanced crystal volume. Crystal structures with a more optimum magnetization can be stabilized with non- $3 d$ elements, such as $\mathrm{B}$ and $\mathrm{N}$, to form lower-symmetry (noncubic) compounds; this results in the large magnetocrystalline anisotropy required for coercivity. In RE-based magnets, the stabilizing element is a moment-bearing RE element that not only optimizes the structure but also contributes to the magnetocrystalline anisotropy.

Although a given magnet may exhibit impressive room temperature $(B H)_{\max }, M_{\mathrm{s}}$, and $H_{\mathrm{cJ}}$ values, which are required for a commercially viable magnet alloy, these parameters may diminish rapidly with increasing temperature. This results in significant degradation of the operation of the magnetcontaining device. At the maximum operating temperature, $H_{\mathrm{cJ}}$ must be sufficiently high to resist demagnetization; $M_{\mathrm{s}}$ must simultaneously be high enough to provide the required magnetic flux. In addition, the microstructure and packaging of any magnet must be engineered to be thermodynamically and physically stable (resistant to corrosion, decomposition, or oxidation) in the operating environment. RE-based magnets, for example, are prone to rapid decomposition in wet, warm, or corrosive environments if not adequately encased in a protective coating $(31,32)$. Because the expected lifetime of a magnet-containing device may exceed 10 years (in the case of traction drive motors) or 25 years (in the case of generators), losses in magnetic performance from environmental degradation must be carefully controlled. An alternative, enhanced TM magnet material must also have a reasonable degree of mechanical strength and toughness, i.e., the ability to withstand the physical impacts and bending stresses involved in conveyance, part handling, and insertion into a rotor cavity in a nonmagnetized or, especially, a magnetized state.

\section{MAGNETS AND MANUFACTURING}

The extreme sensitivity of magnet performance to processing conditions can greatly affect magnet manufacturing costs. Some magnets, including some types of high-quality Nd-Fe-B magnets, are composed of isotropic flakes produced directly from the molten alloy by rapid solidification techniques (33). The flakes are magnetically isotropic powder particles, each containing a population of randomly oriented, $\sim 30-50$-nm nanograins. Whereas individual nanocrystalline flakes may exhibit $(B H)_{\max }$ values in the vicinity of 10 to 16 MGOe, the $40 \mu \mathrm{m}$ flakes must be consolidated 
into a bulk magnet of the desired shape by blending with a polymer binder and injection or compression molding. In this case, $(B H)_{\max }$ is reduced by approximately $50 \%$ if a $70 \%$ (by volume) loading of flakes can be achieved. Although bonded isotropic magnets with $(B H)_{\max }$ values of $\sim 8$ MGOe are appropriate for some applications, more expensive approaches are needed for aligned magnets. These costly techniques for achieving magnetic alignment involve processes such as vacuum hot pressing and die upsetting of the ribbon flakes to fully densify the magnets in order to recover $B_{\mathrm{r}}$ and increase $(B H)_{\max }$ to the range of 25 to 30 MGOe.

Various synthesis and processing techniques, such as chill casting and powder metallurgical procedures, can be used to produce anisotropic RE magnets containing crystallographically aligned grains; these techniques yield grain sizes of a few micrometers, much larger than those produced by rapid solidification (38). Magnets produced using the sintered powder process are referred to as sintered magnets. In such magnets, the RE-magnet alloy is first strip cast from the melt to produce large-grained material with a relatively fine-scale solidification microstructure that can avoid extended homogenization annealing. This material is then comminuted by hydrogen decrepitation and milling to the desired particle size, at which each particle is a single crystal grain. These particles are aligned in a magnetic field and precompacted before vacuum sintering to a fully dense, sintered block. Finished magnet blocks are machined into final shapes in a dicing operation.

The cost structures of the two most widely commercialized processes-melt spinning and polymer bonding to create net shapes versus chill casting, milling, hot press sintering, and machining to final shapes-differ significantly on a per-kilogram basis, but because of the large difference in magnetic properties, the magnet production cost as a function of $(B H)_{\max }$ is a more relevant metric. Figure 5 shows approximate manufacturing costs as a function of $(B H)_{\max }$ for many permanent magnets. Because there are various grades and chemistries for many permanent magnet alloys, the colored regions of Figure 5 represent approximate performance and cost ranges. Part of the

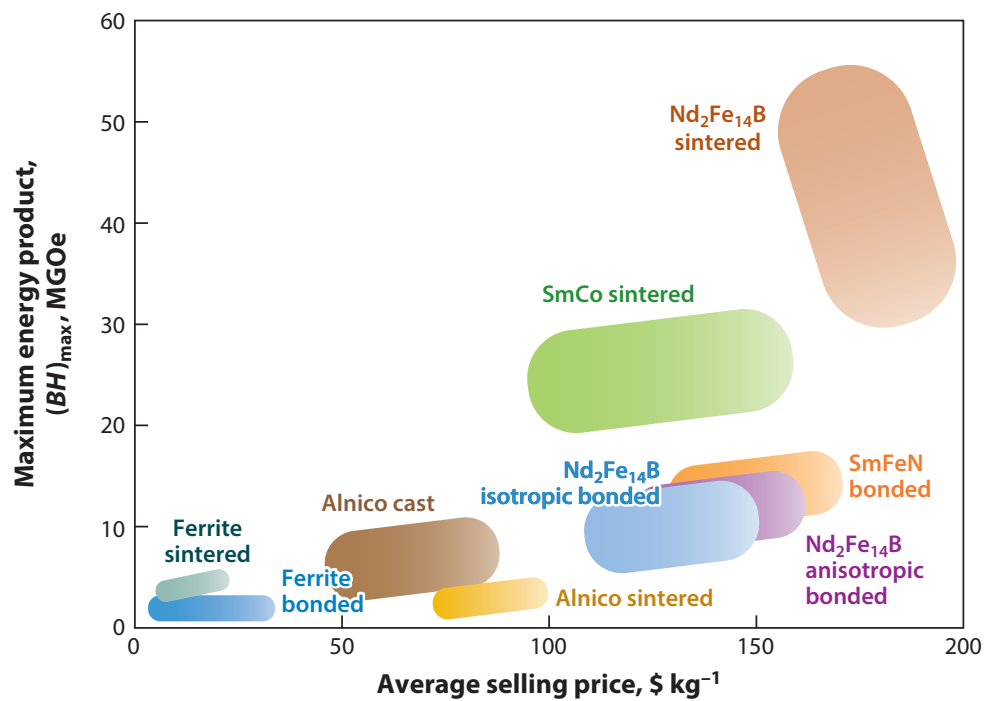

Figure 5

$(B H)_{\max }$ as a function of the average US selling price (in 2012) based on weight for the major commercial magnet classes. The estimated ranges are based on standard shapes and sizes and do not reflect factors such as complexity and nonstandard shape and size. Figure adapted from Reference 12. Gradient fill is used to indicate that the boundaries are not well defined. 
higher cost associated with the production of RE-based sintered magnets is the resultant large amount of waste. Grinding swarf and saw kerf from dicing operations, as well as brittle magnet breakage, are all produced during the process of turning sintered magnet powder into a finished magnet. This loss is relatively small for large magnets, but it can exceed $50 \%$ for very small magnets.

Machines that incorporate RE magnets are significantly more expensive than other machines because of the high cost of the RE elements. RE-magnet-containing machines are typically more efficient and smaller than other types of permanent magnet machines; however, the efficiency of these machines is reduced by the low electrical resistivity of the metallic, RE-based magnet alloys in the operating components, which enhances eddy current losses in the machine. This problem is not found in machines that use the weaker ferrite permanent magnets that are both nonmetallic and nonconductive and thus do not experience the same dissipative eddy current losses.

To minimize the cost of a motor, the size and shape of the incorporated magnets must always be closely matched to the motor design. Injection molding using magnet powder to synthesize netshaped, bonded, RE magnets allows for great flexibility in shape and size. The resultant isotropic magnet exhibits a 50\% magnetization loss at remanence and a correspondingly downgraded magnetic energy product. The magnetization of isotropic bonded magnets is further reduced by the large dilution effect of the nonmagnetic binder that occupies $\sim 35 \%$ of the magnet volume in injection-molded magnets and 20-25\% of the magnet volume in compression-bonded magnets. These features result in a weaker magnet that is required at larger volumes for machine operation at high torque levels. In principle, an anisotropic bonded magnet would alleviate much of this problem; however, creating an anisotropic magnet using rapid solidification techniques is highly challenging. Achieving the energy density needed for generators and traction motors with isotropic bonded magnets is necessary for efficient operation.

\section{CURRENT AND NEXT-GENERATION PERMANENT MAGNETIC MATERIALS}

Permanent magnet development has historically been driven by the need to supply larger magnetic energy in ever smaller volumes, especially at elevated operation temperatures. As discussed in previous sections, the temperature dependencies of the parameters $(B H)_{\max }, M_{\mathrm{s}}$, and $H_{\mathrm{cJ}}$ are critical factors in electric machine design and performance. These temperature dependencies depend strongly on $T_{\mathrm{c}}$ and on the intrinsic magnetocrystalline anisotropies of the magnetic material. Figure 6 shows the temperature dependencies of the magnetic properties of the most common magnet materials in use today. Any new or improved permanent magnetic material should exhibit elevated temperature performance that meets—or, ideally, significantly exceeds—-the performance of existing magnetic materials.

The search for new or modified permanent magnetic materials may be aided by modern software programs based on DFT. Techniques such as supercell calculations (34) and genetic algorithms $(35,37)$ make it possible to explain observed magnetic properties and allow for a fairly rapid assessment of "what if ?" scenarios for known or postulated compounds (36). This undertaking may be as straightforward as evaluating the properties of substitutions for known compounds and determining their thermodynamic stability. These supercell calculations normally involve the partial substitution of one element on a particular lattice site in a crystal structure with a second element; the size of the unit cell used in the calculation must be increased so that a periodic structure may be obtained, hence the name supercell. Figure 7 gives an example of a supercell for the $\mathrm{L} 1_{0}$ structure.

The search for entirely new compounds can be enhanced by using sophisticated techniques such as genetic algorithms to identify new crystal structures $(35,37)$. These structures must then 


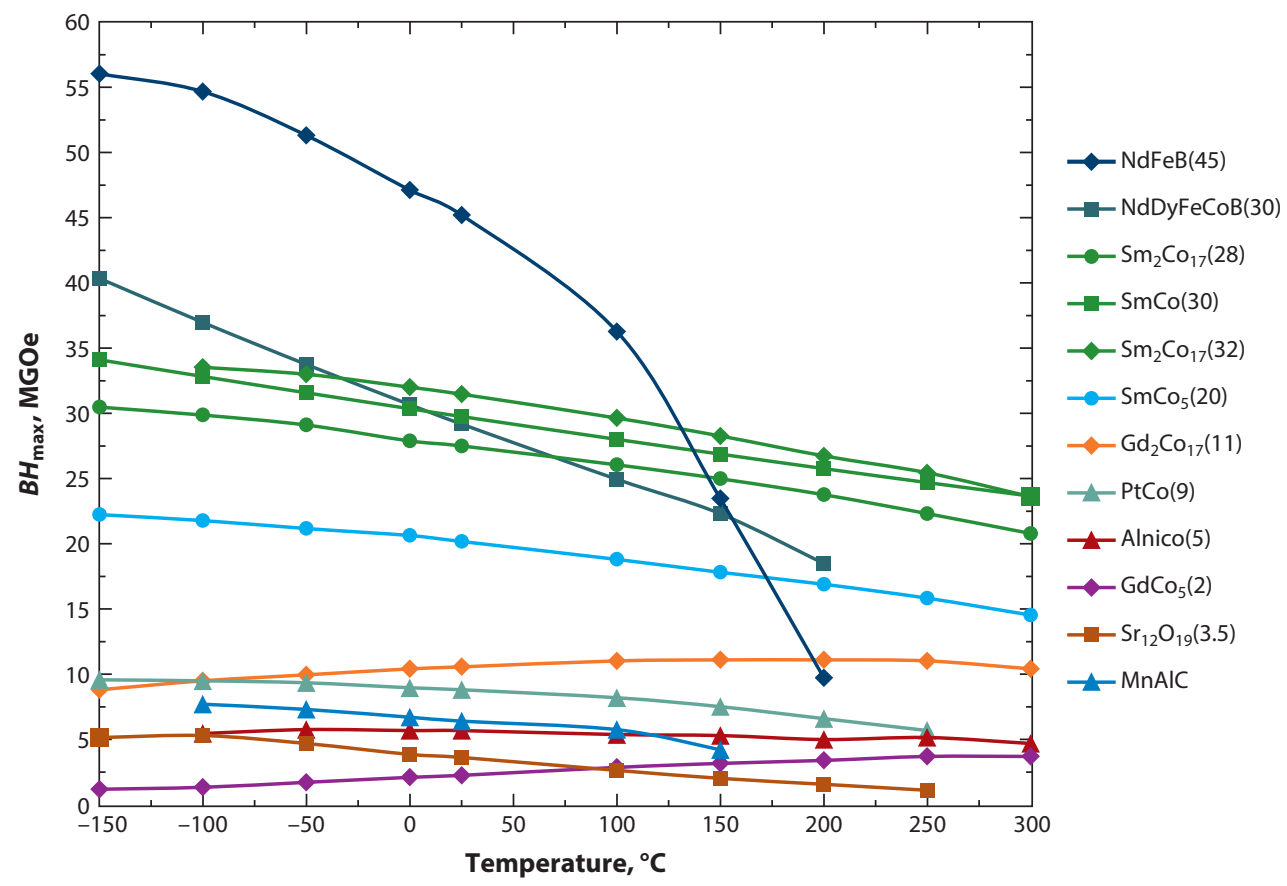

Figure 6

$(B H)_{\max }$ as a function of temperature for the most common commercial magnets and some promising alternatives. The temperature range of interest for demanding applications such as vehicle traction motors and wind turbines is between 150 and $200^{\circ} \mathrm{C}$. Numbers in parentheses denote specific grades.

be evaluated for the high ferromagnetic moments and high magnetocrystalline anisotropy that are critical metrics for the development of promising new permanent magnet compounds (38). Because the resultant magnetocrystalline anisotropy is a combination of the spin-orbit and crystalfield effects, these parameters may be calculated using several DFT programs $(39,40)$.

Low concentrations of interstitial impurities of $\mathrm{C}$ and $\mathrm{N}$ in body-centered cubic (bcc) Fe do indeed modify the hybridization of the Fe $3 d$ orbitals $(41,43)$ and yield a fairly large anisotropy contribution in materials like carbon steel (46) and Fe-N. More important contributions to the magnetic character could result from strain effects arising from the interstitials themselves. Theoretical calculations suggest that compounds containing mixtures of $3 d, 4 d$, and $5 d$ TM elements can have large magnetocrystalline anisotropy via large spin-orbit coupling $(44,45)$. Computational efforts contribute significantly to the search for new or improved permanent magnetic materials.

In this section, we focus on those magnetic compounds with promising characteristics or favorable synthesis pathways where compositional modifications may improve their inherent magnetic properties for potential use in generators and traction motors. In particular, we review and assess the properties of current RE-free magnets such as alnico and ferrite (strontium or barium ferrites and iron oxide) and the prospects for future permanent magnet candidates such as tetrataenite, iron nitride, manganese bismuth, manganese aluminum, and cerium-based intermetallic compounds.

\section{Alnico Magnets}

For the first half of the twentieth century, most permanent magnets were Fe-based steel alloys with $(B H)_{\max }$ values significantly less than 1 MGOe. The first significant improvement in $(B H)_{\max }$ 
a

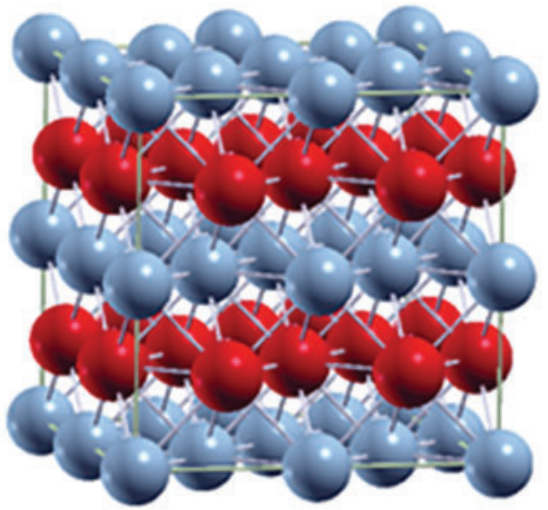

b

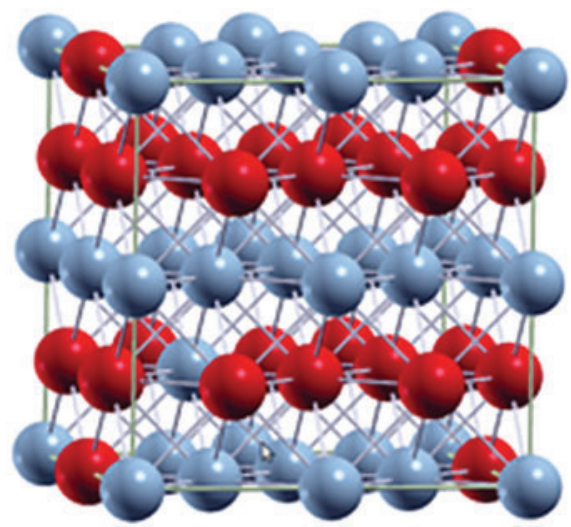

Figure 7

Example of a supercell (32 atoms) used in density functional theory calculations. (a) Perfect $\mathrm{L} 1_{0}$ structure with the composition $\mathrm{A}_{16} \mathrm{~B}_{16}$. (b) Slightly off-stoichiometric structure with an $\mathrm{A}_{17} \mathrm{~B}_{15}$ composition.

was achieved in alnico in the 1930s (27-29). Although other commercially important permanent magnetic materials such as $\mathrm{CoPt}$ and ferrites were also developed in the mid-twentieth century, alnico continued to be the industry standard for high-end permanent magnet applications (22).

Current status. Alnico magnets derive their magnetic strength by virtue of a spinodal phase decomposition from the high-temperature homogeneous composition into a two-phase nanocomposite of ferromagnetic FeCo-rich and essentially nonmagnetic NiAl-rich phases. The magnetization of alnico derives from the FeCo constituent of the alloy, which has a composition corresponding to the highest known $M_{\mathrm{s}}$ and a high $T_{\mathrm{c}}$. This FeCo phase is cubic with three equivalent easy axes; as a result, its $K_{1}$ is more than an order of magnitude smaller than that of the uniaxial $\mathrm{Nd}_{2} \mathrm{Fe}_{14} \mathrm{~B}$ compound (30). This weak magnetocrystalline anisotropy is not sufficient to induce a robust coercivity. However, during a high-temperature annealing process, the alloy spinodally decomposes to form an FeCo phase of elongated parallelepipeds that possess appreciable shape anisotropy.

Whereas early alnico magnets contained randomly oriented FeCo parallelepipeds, an anisotropic microstructure was achieved in the 1950s and 1960s by adopting directional solidification processing and applying a magnetic field during the annealing processes, resulting in the formation of $<001>$-textured, elongated $\mathrm{FeCo}$ precipitates aligned parallel to the direction of the applied magnetic field $(47,48)$. This magnetic annealing procedure creates superior alnico alloys, referred to by their grades (alnico 5-7, alnico 8, and alnico 9), with $(B H)_{\max }$ values of 510 MGOe (40-80 $\mathrm{kJ} \mathrm{m}^{-3}$ ) (49-52). Alnico magnets are composed of a base alloy of 8-13-wt\% Al, $13-28-w t \% \mathrm{Ni}$, and $0-42-\mathrm{wt} \% \mathrm{Co}$, with the balance composed of $\mathrm{Fe}$; a number of minor alloying elements, primarily $\mathrm{Cu}, \mathrm{Ti}$, and $\mathrm{Nb}$, are typically added to this base to promote columnar growth and enhance $H_{\mathrm{cJ}}$.

Optimizing alnico. Alnico has several very promising characteristics: a high $T_{\mathrm{c}}$, low thermal coefficients of $H_{\mathrm{c}}$ and $M_{\mathrm{s}}$, and the ability to magnetize in nonplanar orientations. The weakness of alnico as a permanent magnet lies in its reliance on the shape anisotropy of the FeCo parallelepipeds as a basis of coercivity. Although the shape anisotropy in this magnet is limited, analysis 
Alnico 5-7

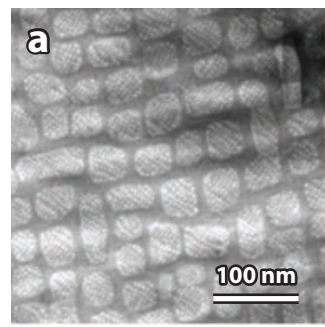

bcc

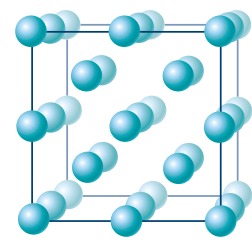

$\mathrm{Fe}, \mathrm{Co}, \mathrm{Ni}, \mathrm{Ti}, \mathrm{Al}$
Alnico 8

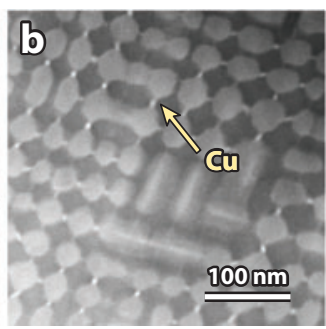

B2

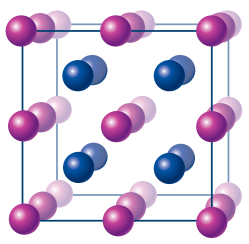

C Co, $\mathrm{Ni}$

$\mathrm{Fe}, \mathrm{Ti}, \mathrm{Al}$
Alnico 9

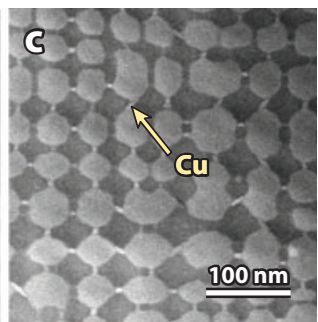

$\mathbf{L 2}_{1}$

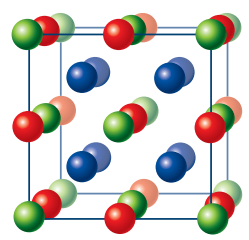

$\mathrm{Fe}, \mathrm{Ti}$

Al

$\mathrm{Co}, \mathrm{Ni}$

Figure 8

High-angle annular dark-field scanning transmission electron microscopy images of $(a)$ alnico 5-7, (b) alnico 8, and $(c)$ alnico 9 . The regular array of light gray squares or rectangles is $\mathrm{Fe}-\mathrm{Co}$ in a bcc or B2-ordered structure. This phase is strongly ferromagnetic with a large moment. The dark gray in alnico 5-7 is $\mathrm{NiAl}$ with a $\mathrm{B} 2$ structure, whereas it is an $\mathrm{L} 2{ }_{1}$-ordered structure in alnicos 8 and 9 . These phases are weakly magnetic or nonmagnetic.

of alnico indicates that the realized coercivities do not take full advantage of the available magnetocrystalline anisotropy. This deficiency is attributed in part to a nonoptimal microstructural scale that permits magnetization reversal by lower-energy pathways (53). If possible, a doubling of the alnico's $H_{\mathrm{c}}$ without sacrificing $B_{\mathrm{r}}$ would increase $(B H)_{\max }$ from the current best of 10.5 MGOe to $\sim 21$ MGOe.

With renewed interest in RE-free magnets, researchers have used advanced characterization techniques such as orientation imaging microscopy, high-resolution transmission electron microscopy, Lorentz microscopy, and atom probe microscopy to gain new, atomic-level information concerning structural and chemical routes for further optimization of alnico. Although the alnico spinodal decomposition process results in a remarkable, regular nanostructure, high-angle annular dark-field scanning transmission electron microscopy images show that the scale of the resultant nanostructure (Figure 8) is still fivefold greater than is desired for optimum resistance to magnetization reversal (53). Reducing the scale of the nanostructure should produce significant improvements in the anisotropy.

Application of magnetic domain imaging techniques on scales ranging from the optical or micrometer scale to the nanoscale show that the magnetic FeCo parallelepipeds in alnico are exchange coupled to form larger, multigrain interaction domains. This suggests that the primary means of coercivity development in this material is the pinning of interaction-domain walls (L. Zhou, M.K. Miller, P. Lu, L. Ke, R. Skomski, et al., submitted). Reducing the magnetostatic and exchange interactions between the FeCo nanorods in alnico should result in smaller interaction domains and increase the domain wall pinning energy and thereby improve the coercivity. 


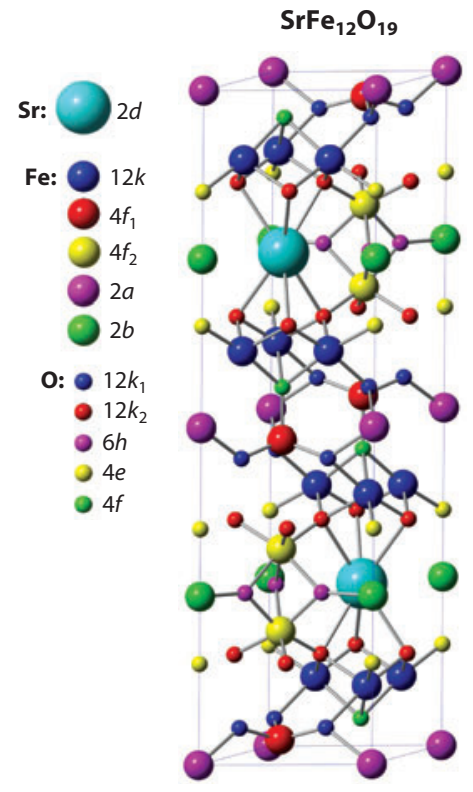

Figure 9

The crystal structure of ferrite magnets. The high ordering temperature of these magnets stems from the strong indirect exchange between Fe atoms mediated by $\mathrm{O}$. This interaction is antiferromagnetic, such that the net moment of the material is a result of unequal moments on the Fe sites.

In addition to structural studies, atom probe measurements have allowed for detailed chemical characterization of the phase evolution, including of metastable transitional phases, accompanying spinodal decomposition of the alnico solid solution. Recently, researchers accurately measured on an atomic scale the composition of the transitional phases during spinodal decomposition of alnico (L. Zhou, M.K. Miller, P. Lu, L. Ke, R. Skomski, et al., submitted) and the role of the applied magnetic field on the formation of the spinodal (54). These advances have improved characterization of the constituent phase properties in alnico and have fostered new avenues for increasing coercivity.

\section{Ferrite Magnets}

Prior to the 1950s, permanent magnets were based on magnetic steels. Even alnico resulted from studies to improve the properties of those steels. In 1952, a new class of permanent magnet based on a class of oxides with a hexagonal crystal structure was discovered (Figure 9) (55). These compounds adopt a hexagonal crystal structure and are described by the formula $\mathrm{MO}-6 \mathrm{Fe}_{2} \mathrm{O}_{3}$ or $\mathrm{MO}-2 \mathrm{Fe}_{2} \mathrm{O}_{4}-6 \mathrm{Fe}_{2} \mathrm{O}_{3}$, where $\mathrm{M}$ is $\mathrm{Ba}, \mathrm{Sr}$, or $\mathrm{Pb}$ and $\mathrm{O}$ is oxygen. For toxicological reasons, $\mathrm{Pb}$-based compounds are not used as commercial magnets. The Ba-containing composition is a highly successful permanent magnetic material known as barium ferrite or barium hexaferrite; it is often simply referred to as a ceramic magnet.

The ferrite family of oxides exhibits high coercivity but rather low magnetization. Unlike metallic magnets, the hexaferrites are ferrimagnetic, with both ferromagnetic coupling and antiferromagnetic coupling between Fe magnetic moments. This magnetic coupling scheme is determined by the specific positions within the oxide sublattice of the metallic cations, and by associated 
bonding, through oxygen-mediated, indirect superexchange interactions (56). Doping of selective Fe sites with Co atoms results in significant enhancements of $B_{\mathrm{r}}$ and $H_{\mathrm{cJ}}$ when such doping is paired with La atomic substitution on the $\mathrm{Ba} / \mathrm{Sr}$ site, but phase stability limits the extent of doping. This scenario results in ferrimagnetism: Two ferromagnetic sublattices are antiferromagnetically coupled such that the resultant net magnetization of the compound is determined by the difference between the two sublattice magnetizations. The $M_{\mathrm{s}}$ of these materials is approximately $25 \%$ of that of Nd-based permanent magnets and $33 \%$ of that of alnico (57), with the highest grade of ferrites exhibiting a $(B H)_{\max }$ of 4 MGOe at room temperature $(33$, p. 319). The directional coupling of the superexchange interaction in ferrites provides reasonable anisotropy with an easy magnetization direction along the hexagonal $c$-axis of the unit cell.

Although the overall ferrite magnetization can be increased by selectively reducing the magnetization of one sublattice (thereby reducing the difference in moment between the two sublattices), this action inevitably decreases the interatomic exchange, resulting in a reduced $T_{\mathrm{c}}$. The ferrites have $T_{\mathrm{c}}$ values near $450^{\circ} \mathrm{C}$, but as the magnetic sublattices have individual temperature dependences, the overall magnetization exhibits a high sensitivity to temperature of approximately $-0.2 \% \mathrm{~K}^{-1}$, which is more than 10 times that of alnico. The ferrite magnetocrystalline $H_{\mathrm{A}}$, and

hence the $H_{\mathrm{ci}}$, are also determined by the temperature dependence of the individual sublattice anisotropies. As a result, $H_{\mathrm{ci}}$ increases with increasing temperature-a unique property among commercial magnets. At $-40^{\circ} \mathrm{C}$, the ferrite $H_{\mathrm{ci}}$ is reduced to such an extent that electric machines containing this material are only marginally operable in higher latitudes during the coldest part of the winter.

By weight, ferrites are by far the largest single class of permanent magnets. They are made with inexpensive elements, are easy to process, and, as oxides, have excellent corrosion stability for electric machine applications. However, their low magnetization requires large volumes of material to generate sufficient flux for machine operation: The size of a permanent magnet-based electric machine would be too large for a hybrid vehicle. For wind turbine applications, the cost of the additional structure to support a more massive nacelle containing the ferrite-based generator exceeds the incremental cost of incorporating a RE-magnet-based generator for this application.

\section{Other Fe-Based Compounds Without Rare Earth Elements}

Fe-based magnetic compounds with high Curie temperatures and large magnetizations are relatively common. However, these compounds tend to have low magnetic anisotropy. One strategy for developing strong magnetic anisotropy, supporting permanent magnet behavior, is to engineer magnetic materials with lower-symmetry crystal structures. These structures (typically hexagonal or tetragonal) foster high magnetocrystalline anisotropy along a symmetry axis.

FeNi (tetrataenite). One example of a lower-symmetry structure is the tetragonal $\mathrm{AuCu}-\mathrm{II}$ or $\mathrm{L1}_{0}$ structure (Figure 10), which forms in several binary, nominally equiatomic TM compounds. The $\mathrm{L} 1_{0}$ structure consists of chemically ordered atomic layers of two disparate atomic species that alternate along the tetragonal $c$-axis. Well-known magnetic compounds with the $\mathrm{L} 1_{0}$ structure, such as FePt and FePd, derive from this lower-symmetry crystal structure the high magnetization and significant magnetocrystalline anisotropy necessary for advanced permanent magnet applications. However, these compounds are under consideration only for thin-film-based devices for applications in magnetic recording because of the high cost of $\mathrm{Pt}$ and $\mathrm{Pd}$, which precludes their use as components in bulk permanent magnets for motors and generators.

One interesting example of a bulk ferromagnetic TM-based L $1_{0}$ compound with high magnetocrystalline anisotropy is tetrataenite, found in many stony, stony-iron, and iron-nickel meteorites 


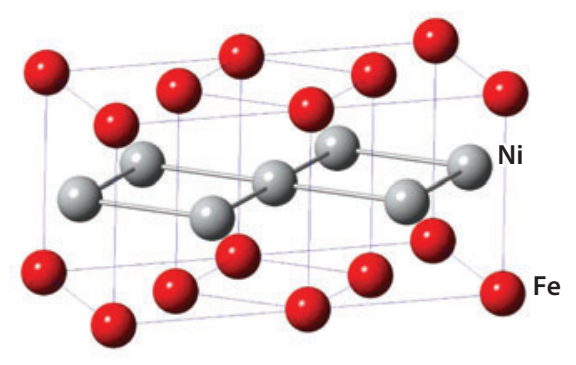

Figure 10

The crystal structure of tetrataenite $\left(\mathrm{L}_{0}\right.$-ordered $\left.\mathrm{FeNi}\right)$. The layered structure results in high anisotropy.

(58). Tetrataenite has relatively high magnetocrystalline anisotropy and a magnetization equal to that of $\mathrm{Nd}_{2} \mathrm{Fe}_{14} \mathrm{~B}$ and is predicted to be an excellent candidate for permanent magnet applications. Unfortunately, in the FeNi binary system, the chemically ordered $\mathrm{L}_{0}$ structure is only marginally more stable than the disordered (A1-type face-centered cubic) structure, which is entropically stabilized above the equilibrium chemical order-disorder temperature $\left(T_{\text {order-disorder }}\right)$ of $320^{\circ} \mathrm{C}$. The Fe-Ni interdiffusion rates for $T<T_{\text {order-disorder }}$ are so slow that, even for the very limited diffusional motion required to achieve local chemical ordering, the $\mathrm{L}_{0}$ structure does not form under normal laboratory conditions but requires astronomically slow cooling rates (on the order of millions of years), the same timescale as that for meteorites.

The main challenge that must be overcome to realize a tetrataenite-based permanent magnet is development of a kinetic pathway to form the hard magnetic $\mathrm{FeNi} \mathrm{L} 1_{0}$ structure in an industrially viable process on terrestrial timescales. The mere existence of this phase suggests that all possible permutations of Fe-based systems have not been fully exploited. Thermodynamic calculations, in-depth first-principles computational studies, and more comprehensive screening tools (such as combinatorial analysis to assess phase formation and stability) will be required to more fully investigate this phase space. Advanced, far-from-equilibrium processing will be needed to explore new phase space for compounds to realize high magnetocrystalline anisotropy with reasonable magnetization via chemical substitutions and unconventional processing methods, as well as to induce chemical ordering in this RE-free system (59).

$\alpha^{\prime \prime}-\mathrm{Fe}_{16} \mathbf{N}_{2}$ (iron nitride). The technologically important magnetic properties of ferromagnetic, TM-containing compounds may also be enhanced by inserting $\mathrm{N}$ into interstitial lattice sites to form TM nitrides (60-62). Interstitial $\mathrm{N}$ alters the TM interatomic spacing, thereby altering the magnetization, magnetocrystalline anisotropy, and $T_{\mathrm{c}}$ of the parent compound. The only commercialized nitride permanent magnet is based on the ferromagnetic $\mathrm{RE}$ compound $\mathrm{Sm}_{2} \mathrm{Fe}_{17}$, which illustrates both the advantages and limitations of this type of material. In these materials (abbreviated here as $\mathrm{SmFeN}$ ), interstitial $\mathrm{N}$ in the lattice changes the Fe-Fe interatomic spacing, increases $T_{\mathrm{c}}$, and provides uniaxial anisotropy. The combination of these effects produces a high-energyproduct magnet powder that is used to form bonded magnets. However, the near- $100 \%$ density required for magnets used in traction motor or wind turbine applications cannot be obtained in this compound because the interstitial $\mathrm{N}$ content is unstable during sintering; $\mathrm{Sm}_{2} \mathrm{Fe}_{17} \mathrm{~N}_{3}$ decomposes into $\mathrm{SmN}$ and Fe phases at temperatures lower than those required for sintering $(60,63)$.

Shifting our discussion to RE-free parent materials with the potential for permanent magnet behavior, some TM-N compounds have large magnetic moments and may be amenable for 
production in appreciable volume at low cost. Two metastable, Fe-based, interstitially modified compounds have generated considerable interest in this context: the tetragonal $\alpha^{\prime \prime}-\mathrm{FeN}$ phase with $\sim 10$ at $\%$ (atomic percent) $\mathrm{N}$ and the chemically ordered $\alpha^{\prime \prime}-\mathrm{Fe}_{16} \mathrm{~N}_{2}$ compound (64). For permanent magnet applications, interest has focused on $\alpha^{\prime \prime}-\mathrm{Fe}_{16} \mathrm{~N}_{2}$. This compound forms metastably in a body-centered tetragonal symmetry based on the $\alpha-\mathrm{Fe}$ (bcc) structure, with $\mathrm{N}$ atoms chemically ordered into interstitial sites. The $M_{\mathrm{s}}$ of $\alpha^{\prime \prime}-\mathrm{Fe}_{16} \mathrm{~N}_{2}$ is $\sim 2.3 \mathrm{~T}$ at $4.2 \mathrm{~K}$, a value that is $\sim 6 \%$ higher than that of pure $\mathrm{Fe}$ and $\sim 25 \%$ greater than that of $\operatorname{Pr}_{2} \mathrm{Fe}_{14} \mathrm{~B}$ at the same temperature. Interestingly, at $4.2 \mathrm{~K}$, the $K_{1}$ of $\alpha^{\prime \prime}-\mathrm{Fe}_{16} \mathrm{~N}_{2}$ is estimated to be $1 \times 10^{7} \mathrm{erg} \mathrm{cm}^{-3}$, which is half that of $\mathrm{Pr}_{2} \mathrm{Fe}_{14} \mathrm{~B}$ at the same temperature (65). $\left(\mathrm{Nd}_{2} \mathrm{Fe}_{14} \mathrm{~B}\right.$ undergoes a spin reorientation at low temperatures, so a comparison between the magnetic behavior of $\alpha^{\prime \prime}-\mathrm{Fe}_{16} \mathrm{~N}_{2}$ and that of the more commonly used $\mathrm{Nd}_{2} \mathrm{Fe}_{14} \mathrm{~B}$ is not valid in this temperature regime.) The $\alpha^{\prime \prime}-\mathrm{Fe}_{16} \mathrm{~N}_{2}$ compound has been produced in bulk using hydrogen reduction of $\mathrm{Fe}_{2} \mathrm{O}_{3}$ nanoparticles followed by a nitriding treatment with ammonia. A detailed study of the thermal decomposition process of $\alpha^{\prime \prime}-\mathrm{Fe}_{16} \mathrm{~N}_{2}$ revealed that atomic rearrangement results in the formation of $\alpha^{\prime}-\mathrm{Fe}$ and $\gamma^{\prime}-\mathrm{Fe}_{4} \mathrm{~N}$, with associated destruction of technologically useful magnetic properties (66). Unfortunately, at $200^{\circ} \mathrm{C}$ and in an inert atmosphere, $90 \%$ of the $\alpha^{\prime \prime}-\mathrm{Fe}_{16} \mathrm{~N}_{2}$ phase decomposes to the above products in fewer than $20 \mathrm{~h}$. This behavior is typical of TM-N compounds, which either are metastable or possess a moderately low decomposition temperature that limits the techniques that may be employed to process the material (67-69).

As with $\mathrm{Sm}_{2} \mathrm{Fe}_{17} \mathrm{~N}_{3}$, nitride compounds may be suitable for bonded magnet applications, but the higher energy densities of fully dense magnets are required for most traction motor designs. If we assume that powders of such FeN-based phases can indeed be densified, even compounds of moderate decomposition temperatures $\left(\sim 400^{\circ} \mathrm{C}\right)$ have significant drawbacks for electric machine applications because they are likely to experience unacceptable, irreversible magnetization and coercivity losses over time and at moderately elevated operating temperatures. The challenge for producing usable permanent magnets from this class of compounds is to stabilize their metastable crystal structures to allow consolidation into dense monolithic parts with long-term physical and chemical stability (70).

\section{Mn-Based Ferromagnetic Compounds}

Ferromagnetic Mn-based alloys, including MnBi and MnAl, were considered as candidate materials for permanent magnets almost five decades ago. $\mathrm{Mn}$ is an especially interesting TM element: Not only does it have the largest atomic moment of the $3 d$ elements, but it can also adopt a variety of bonding environments by virtue of its numerous oxidation states and is often antiferromagnetic (71). In the equiatomic compounds $\mathrm{MnBi}$ and $\mathrm{MnAl}$, the $\mathrm{Mn}-\mathrm{Mn}$ interactions yield ferromagnetic order. However, the total magnetization in these compounds tends to be low, as the stoichiometry translates to a small volume fraction of magnetic atoms, resulting in a low magnetic energy density. Nonetheless, when properly engineered, these compounds can deliver moderate $(B H)_{\max }$ values (7-12 MGOe) that are appropriate for applications that do not require extremely high magnetic energy densities.

MnBi (manganese bismuth). The low-temperature phase (LTP) form of MnBi crystallizes in the hexagonal NiAs-type structure (Figure 10) (72, 73), which features a hexagonal packing of $\mathrm{Mn}$ and $\mathrm{Bi}$ atoms filling half the bipyramidal interstitial sites (74). This atomic arrangement results in a layered structure that, in conjunction with the large spin-orbit coupling of the $5 d$ electrons of $\mathrm{Bi}$, provides a high $H_{\mathrm{A}}$ to this compound. Intriguingly, the $H_{\mathrm{c}}$ of $\mathrm{MnBi}$ increases with increasing temperature (75). At $10 \mathrm{~K}$, the LTP MnBi magnetization lies in the hexagonal 
basal plane, reflecting an easy-plane magnetization direction, but rotates to the $c$-axis at $\sim 90 \mathrm{~K}$ (76). The low melting temperature of $\mathrm{Bi}$ and the high vapor pressures of $\mathrm{Mn}$ and $\mathrm{Bi}$ have posed some challenges for synthesizing and processing this compound into a commercially viable magnetic material. $\mathrm{MnBi}$ may be formed using rapid solidification techniques that provide an isotropic distribution of grain orientations, decreasing the potential $(B H)_{\max }(77)$. Anisotropic, fully dense, $\mathrm{MnBi}$-based materials have been produced by arc melting followed by low-temperature ball milling and hot compaction into a densified solid, with room-temperature remanent magnetization, $M_{\mathrm{r}}$, values of $\sim 0.64 \mathrm{~T}$ and $H_{\mathrm{ci}}$ of $\sim 11-12 \mathrm{kOe}(78)$. The anticipated $(B H)_{\max }$ of $\mathrm{MnBi}$ is $\sim 6-7 \mathrm{MGOe}$ at room temperature, with a $T_{\mathrm{c}}$ limited by decomposition of the magnetic phase through a peritectic reaction at $355^{\circ} \mathrm{C}(79)$.

MnAl (manganese aluminum). The metastable $\tau$-phase of $\mathrm{MnAl}$ forms in the $\mathrm{L} 1_{0}$-structure type from the high-temperature parent hexagonal close-packed (hcp) $\varepsilon$-phase by a massive transformation (80). During bulk synthesis, the high-temperature hcp $\varepsilon$-phase must be first formed and then transformed through a diffusive nucleation and growth process to realize the $\tau$-phase. The room temperature $K_{1}$ of $\tau$-phase $\mathrm{MnAl}$ is estimated to be on the order of that of $\mathrm{Nd}_{2} \mathrm{Fe}_{14} \mathrm{~B}$, but $M_{\mathrm{s}}$ is only $\sim 40 \%$ of that of $\mathrm{Nd}_{2} \mathrm{Fe}_{14} \mathrm{~B}$. These parameters combine to yield a theoretical $(B H)_{\max }$ of $\sim 12$ MGOe at room temperature with a low density of $5.2 \mathrm{~g} \mathrm{~cm}^{-3}$, highlighting $\mathrm{MnAl}$ as a material with an attractive energy density per unit mass (81-83). The processing of $\mathrm{MnAl}$ permanent magnets is complicated by the metastable nature of parent $\varepsilon$-phase $\mathrm{MnAl}$ at the $\tau$ phase formation temperature and by the competing decomposition reaction of the ferromagnetic $\tau$-phase into two equilibrium paramagnetic phases. As a result of these unique phase relationships, $\mathrm{MnAl}$ heat treatment must be optimized to maximize $\tau$-phase formation while minimizing $\tau$ phase decomposition $(71,84)$. The nonequilibrium processing techniques of mechanical milling and melt spinning are viable methods for producing this metastable phase while retaining the fine-grain structure required for high coercivity. However, these techniques produce an isotropic grain structure, reducing the $B_{\mathrm{r}}$.

The stability of the $\mathrm{MnAl} \tau$-phase may be increased by adding $\mathrm{C}$, but at a cost. For example, $\sim 0.5 \mathrm{wt} \% \mathrm{C}$ addition yields significant decreases in $H_{\mathrm{A}}$ (from 55 to $39 \mathrm{kOe}$ ) and $T_{\mathrm{c}}$ (from 380 to $\left.285^{\circ} \mathrm{C}\right)(85)$. Typical $H_{\mathrm{cJ}}$ values reported in the literature for $\mathrm{MnAl}$ and $\mathrm{MnAl}(\mathrm{C})$ alloys produced by melt spinning followed by appropriate heat treatment are on the order of 1,500 to 2,000 Oe $(86,87)$, with observed experimental maximum energy products of $\sim 4-7$ MGOe (37$\left.56 \mathrm{~kJ} \mathrm{~m}^{-3}\right)(83,88)$. Improved microstructural control can provide improved structure-sensitive magnetic properties. For example, single-phase $\mathrm{L}_{0}$-type $\mathrm{MnAl}(\mathrm{C})$ processed by mechanical milling exhibits reduced grain sizes that provide a dramatic increase in $H_{\mathrm{c}}$ from $\sim 1,700$ Oe to 4,000 Oe, the highest reported $H_{\mathrm{c}}$ to date for $\mathrm{MnAl}(\mathrm{C})(67)$.

The temperature stability of the $\mathrm{MnAl} \tau$-phase is of concern, as prolonged annealing at 400$700^{\circ} \mathrm{C}$ decomposes the binary phase (90). Although $\mathrm{C}$ additions to $\mathrm{MnAl}$ can stabilize the ferromagnetic $\tau$-phase, the accompanying degradation of the magnetic properties is unacceptable for many permanent magnet applications. The identification of an alloying element that increases the stability of the $\tau$-phase without degrading its magnetic properties will be key to making $\mathrm{MnAl}$ a viable permanent magnet.

\section{Exchange Spring Permanent Magnets}

Although permanent magnets have been demonstrated in the $\mathrm{MnBi}$ and $\mathrm{MnAl}$ systems with $(B H)_{\max }$ values exceeding those of the hard ferrites, processing difficulties and the low thermal stability of these systems have prevented their significant penetration into the permanent magnet 
market. Important challenges must be overcome to increase their operating temperature capability and magnetization. Increasing the operating temperature in $\mathrm{MnBi}$ is particularly problematic because the stability of the $\mathrm{MnBi}$ phase, not the strength of the inherent $\mathrm{Mn}-\mathrm{Mn}$ interatomic exchange interaction, limits high-temperature operation. Thus, a large temperature excursion experienced by a MnBi-based magnet would not only cause demagnetization but also result in the formation of a highly detrimental liquid phase within the machine because of its equilibrium $\mathrm{MnBi}$ decomposition temperature of $355^{\circ} \mathrm{C}(73)$. The operating temperature of most generators and traction motors is limited to temperatures considerably less than $355^{\circ} \mathrm{C}$ by the thermal stability of other components, in particular of the insulating materials, so $355^{\circ} \mathrm{C}$ is not an engineering limit. However, ternary alloying additions to $\mathrm{MnBi}$ that could increase $M_{\mathrm{s}}$ tend to reduce the peritectic decomposition temperature, limiting choices for alloy improvement $(91,92)$. On a more positive note, the elevated-temperature $\left(127^{\circ} \mathrm{C}\right)$ coercive field noted for $\mathrm{MnBi}$ is nearly five times that of Nd-based compounds at the same temperature (93).

If the phase stability issues inherent in the $\mathrm{MnAl}$ and $\mathrm{MnBi}$ systems can be addressed, a promising hybrid material could result in the creation of a high-energy-product, RE-free magnet. This could occur via nanostructural development of a material consisting of $\mathrm{MnBi}$ or $\mathrm{MnAl}(\mathrm{C})$ interstitially modified to enhance $T_{\mathrm{c}}$, combined with a high-moment bcc $\alpha^{\prime}$-Fe or FeCo phase, to create a nanocomposite magnetic system — a magnetic exchange spring — that ideally exhibits the best technical attributes of both constituent phases (94). Isotropic exchange spring magnets are commercially produced in the form of Fe-rich, melt-spun $\mathrm{NdFeB}$ with an overall composition that allows the magnetically hard $(\mathrm{NdFeB})$ and magnetically soft $(\mathrm{Fe})$ phases to be in equilibrium in the phase diagram. As in the case of other hard-soft systems, the realization of a Mn-based, magnetically hard phase intimately coupled to an Fe or FeCo soft phase at the nanoscale, without interference from detrimental interdiffusion during processing, represents an extreme challenge for nonequilibrium synthesis and processing techniques. If the creation of a RE-free magnetic nanocomposite with strongly exchange-coupled phases were indeed possible, such a nanocomposite could replace the lower-end (isotropic), RE-containing magnets, delivering an anticipated $(B H)_{\max }$ in the range of 10 to 15 MGOe (80 to $120 \mathrm{~kJ} \mathrm{~m}^{-3}$ ) at room temperature.

\section{Permanent Magnets Made from Nonstrategic Rare Earth Elements}

Although the RE elements are chemically very similar, their relative natural abundance within the earth's crust varies by roughly two orders of magnitude. RE elements occur in groups in nature and must be processed as such; thus, the ratio of supply to demand is much greater for some elements, notably Ce and La, than for heavier elements such as Dy. As a result, the strategic supply concern is not uniform across the lanthanide series. Only a few RE elements currently have high market demand, both in absolute terms and, more importantly, relative to their natural abundances in commercially viable mines. The most critical supply risks in the next 5 years are associated with $\mathrm{Dy}, \mathrm{Eu}, \mathrm{Nd}, \mathrm{Tb}$, and $\mathrm{Y}$, whereas those associated with $\mathrm{Ce}, \mathrm{La}$, and, to some extent, $\operatorname{Pr}$ are much less critical (8). In terms of resources, Ce composes nearly $40 \%$ of all RE elements in the earth's crust (95), and in light-RE-element deposits, such as those found at Mountain Pass, California, the Ce concentration can be as high as $50 \%$. Conversely, Dy-which is critical for the high-temperature capability of $\mathrm{Nd}(\mathrm{Pr}) \mathrm{FeB}$ alloys as well as for other applications such as light sources and computer displays - accounts for less than $2 \%$ of all the RE elements and is found in abundance in only a few localities worldwide. The elements $\mathrm{Ce}, \mathrm{La}, \mathrm{Nd}$, and $\operatorname{Pr}$ (ranked in order of decreasing abundance) make up $90 \%$ of the global RE supply and as such are the only suitable elements for application as major components of magnets produced in large volumes. Successful 
development of ferromagnetic alloys that use the most abundant RE elements, La and Ce, will help mitigate excessive demand on $\mathrm{Nd}$ and, more importantly, on Dy; at the same time, it will increase market demand for these underused elements, providing a higher return on investment for light-RE-element mines.

Unfortunately, these two elements are not well suited to permanent magnet applications. La, having no $f$ electrons, does not have a magnetic moment and hence functions only as an atomic spacer in a given crystal structure. Ce is not well behaved because of its unusual electronic structure. When combined in intermetallic compounds with the $3 d$ TM elements $\mathrm{Fe}$, Co, or $\mathrm{Ni}$, Ce has a strong tendency to donate its single $4 f$ electron and adopt a $4^{+}$valence or a mixed-valence configuration rather than take on the $3^{+}$valence state typical of most other RE elements. Although a Ce $4^{+}$ion, with no $4 f$ electrons, might be expected to behave like the nonmagnetic RE elements $\mathrm{La}, \mathrm{Lu}$, and $\mathrm{Y}$ with little effect on $T_{\mathrm{c}}$ and no contribution to the magnetocrystalline anisotropy, this has not been experimentally verified. In intermetallic TM compounds, Ce appears to adopt a mixed-valence configuration that results in hybridization of the $\mathrm{Ce} 4 f$ electrons with the TM $3 d$ electrons, reducing $T_{c}$. Ce analogs such as $\mathrm{Ce}_{2} \mathrm{Fe}_{14} \mathrm{~B}$ (96) and $\mathrm{Ce}_{2} \mathrm{Fe}_{17}$ (97) have $T_{\mathrm{c}}$ values $\sim 150^{\circ} \mathrm{C}$ lower than their isostructural RE-based magnetic compounds, which prevents their use in most permanent magnet applications. Two Ce-Co binary compounds- $\mathrm{Ce}_{2} \mathrm{Co}_{17}$, with a $T_{\mathrm{c}}$ of $805^{\circ} \mathrm{C}(98)$, and $\mathrm{CeCo}_{5}$, with a $T_{\mathrm{c}}$ of $368^{\circ} \mathrm{C}(99)$ - have potential as permanent magnets; however, heavy use of $\mathrm{Co}$ is undesirable because of potential supply vulnerabilities. The challenge for developing a commercially viable Ce-based magnet is design of a structure with detailed chemistry that can compensate for the detrimental properties of Ce in compounds with large atomic fractions of Fe or Mn.

\section{OUTLOOK AND CONCLUSIONS}

RE elements play many roles in the compounds that provide the basis for high-performance permanent magnets. Structurally, RE elements are large atoms that can stabilize noncubic structures and produce the potential for realization of large magnetocrystalline anisotropy. These lowersymmetry structures also provide controlled interatomic (TM-TM) spacings favorable for ferromagnetic interactions. Magnetically, the lanthanide $4 f$ electrons have large magnetocrystalline anisotropies, but they have relatively low-volume magnetic moments, which reduce their $M_{s}$. The $4 f$ electron orbits are spatially limited and thus tend to have minimal orbital overlap that decreases the $T_{\mathrm{c}}$ of the material. This feature, when manifest in Fe-based RE intermetallic compounds, compromises the high-temperature performance of the material.

The key intrinsic factors to be considered when investigating new or modified permanent magnet compositions to replace existing RE magnets are $T_{\mathrm{c}}, K_{1}$, and $M_{\mathrm{s}}$. Although $T_{\mathrm{c}}$ strictly limits usage, provided that it is sufficiently above the operating window for the electric machines, it places an absolute limit on the temperature dependence of the extrinsic properties $B_{\mathrm{r}}$ and $H_{\mathrm{cJ}}$. (This statement is not rigorously correct for some of the systems discussed here, as the magnetic ordering temperature in those compounds is determined by the upper limit of the phase stability of the ferromagnetic phase and not by the strength of the exchange interaction.) Large, negative temperature coefficients for $B_{\mathrm{r}}$ and $H_{\mathrm{cJ}}$ require motor designs that are based on maximum operating temperatures and that compensate for significantly degraded magnet properties. Limiting the maximum operating temperature typically requires additional cooling of the motor, which consumes more power, to prevent drastic changes in motor performance as a function of temperature.

How closely a magnet can achieve the theoretical limits of $B_{\mathrm{r}}$ and $H_{\mathrm{c}}$ depends on the microstructure of the magnet. Ideally, the grain size should be crystallographically aligned and highly uniform 
with smooth boundaries. Luckily, the nucleation of reverse domains can be inhibited or domain walls can be pinned once they form in grains that are an order of magnitude larger than the single domain size. To achieve this, researchers must eliminate irregularities at the boundaries of the grain that are accompanied by regions of high flux concentration and that reduce the area of the domain wall required to nucleate a reverse domain. When $H$ equals zero, the magnetization of a constituent grain will lie along its easy axis, and the total magnetization of the magnet is the vector sum of these individual grains along the direction of the bulk magnetization; thus, the degree of grain alignment plays a significant role in determining $M_{\mathrm{r}}$. The maximum energy product of a magnet comprised of highly crystallographically-aligned grains can reach four times that of an isotropic magnet. To introduce a new magnet material into the market, processes must be developed to produce highly uniform microstructures with these desired characteristics. In many of the systems discussed in this review, the range of process parameters that can be used is severely restricted by the phase stability of the parent phase.

The push to reduce greenhouse gases will require a restructuring of energy production and use. Electric machines for both power generation and traction motors can figure prominently in this new economy. Although Nd-based permanent magnet electric machines provide an obvious power-to-weight advantage over induction machines, the availability and price of RE metals presently make permanent magnet-based electric machines less favorable. Of particular concern are the cost and availability of $\mathrm{Dy}$, which has limited availability but is required to improve the high-temperature performance of Nd-based alloys in generators and traction motors. Alternatives to RE-based alloys do exist but currently lack the energy density necessary to replace Nd-based magnets. Some of these potential replacements actually exceed the performance of Nd-based alloys above $200^{\circ} \mathrm{C}$. Many of these compounds have been known for decades, but serious interest in their optimization waned once RE element-based compounds were discovered.

Fortunately, researchers have new tools with which to characterize, understand, and tailor the mechanisms for coercivity and magnetization in these compounds. Experimental methods for exploring wide areas of phase space are also being used to identify new magnetic compounds. Computational tools can provide detailed descriptions of the relationship among atomic composition, order, and interaction of the magnetic spins. These techniques can even be used to discover new compounds. Significant research efforts are under way to exploit these possibilities. As was the case in the 1980s with the global supply disruption of Co, a shortage of critical materials can be a boon for materials discovery.

\section{DISCLOSURE STATEMENT}

The authors are not aware of any affiliations, memberships, funding, or financial holdings that might be perceived as affecting the objectivity of this review.

\section{ACKNOWLEDGMENTS}

This work was supported by the US Department of Energy, Office of Energy Efficiency and Renewable Energy, Vehicle Technologies Office, through Ames Laboratory, which is operated by Iowa State University under contract DE-AC02-07CH11358. L.H.L. gratefully acknowledges support from the Office of Naval Research grant number N00014-10-1-0553 and from the US Department of Energy's Advanced Research Project Agency-Energy (ARPA-E) award number DE-AR0000186. Steve Constantinides of Arnold Magnetic Technologies provided critical magnet market information. We gratefully acknowledge discussions with Liqin Ke, Lin Zhou, P. Manchanda, A. Kashyap, and J.E. Shield regarding publications in progress. 


\section{LITERATURE CITED}

1. Schlemmer HP. 2005. Vom Magneteisenstein zum Magnetresonanztomographen. Zur Geschichte des Megnetismus [From loadstone to magnetic resonance tomography. Historical remarks on magnetism]. Der Radiol. 45:356-62

2. Gilbert W, Dowling A. 1600. De Magnete, Magneticisque Corporibus, et de Magno Magnete Tellure [On the Magnet and Magnetic Bodies, and on That Great Magnet the Earth]. London: Peter Short

3. Karlsruhe Inst. Technol. 2014. The invention of the electric motor 1856-1893. Elektrotech. Inst. http://www.eti.kit.edu/english/1390.php

4. Ohio Electr. Mot. 2013. A historical overview of permanent magnet motors. Obio Electr. Mot. June 26. http://www.ohioelectricmotors.com/a-historical-overview-of-permanent-magnet-motors-1704

5. Dent PC. 2009. High performance magnet materials: risky supply chain. Adv. Mater. Process. 167(8):27-30

6. Normile D. 2010. Haunted by "specter of unavailability," experts huddle over critical materials. Science 330:1598

7. Orlik T, Yap CW. 2012. China's rare earth recoil. Wall Street fournal, March 13

8. US Dep. Energy. 2011. Critical materials strategy. Rep., US Dep. Energy, Washington, DC. http:// energy.gov/sites/prod/files/DOE_CMS2011_FINAL_Full.pdf

9. Moss RL, Tzimas E, Kara H, Willis P, Kooroshy J. 2011. Critical metals in strategic energy technologies: assessing rare metals as supply-chain bottlenecks in low-carbon energy technologies. JRC Publ. No. EUR 24884 EN, Publ. Off. EU, Luxembourg

10. Resnick Inst. 2011. Critical materials for sustainable energy applications. Rep., Resnick Inst., Calif. Inst. Technol., Pasadena, Calif.

11. Phys.org. 2013. China trims rare earth quota for H1 2014. Phys.org. Dec. 13. http://phys.org/news/ 2013-12-china-trims-rare-earth-quota.html

12. Kramer MJ, McCallum RW, Anderson IA, Constantinides S. 2012. Prospects for non-rare earth permanent magnets for traction motors and generators. $7 O M$ 64(7):752-63

13. Constantinides S. 2013. The current state of the permanent magnet industry. Sem., Oak Ridge Natl. Lab., Oak Ridge, Tenn., Sept. 17

14. Metal-Pages. 2014. Metal Prices-Rare Earths. http://www.metal-pages.com/metalprices/rareearths/

15. Constantinides S. 2011. Status and outlook of rare earth permanent magnets. DOE Veh. Technol. Program APEEM R\&D FY12 Kickoff Meet., Oak Ridge Natl. Lab., Oak Ridge, Tenn., Nov. 2-4

16. Jpn. Minist. Econ. Trade Ind., Eur. Comm., US Dep. Energy. 2011. Trilateral EU-Zapan-US conference on critical materials for a clean energy future: Washington DC, 4-5 October 2011. Summ. Rep., US Dep. Energy, Washington, DC. http://energy.gov/sites/prod/files/2013/05/f0/TRILATERAL_CRITICAL_ MATERIALS_WORKSHOP_SummaryReportfinal\%2020111129.pdf

17. Coultate J. 2009. Wind turbine gearbox durability. Wind Systems, July, pp. 43-45

18. Jensen BB, Mijatovic N, Abrahamsen AB. 2013. Development of superconducting wind turbine generators. 7. Renew. Sustain. Energy 5:023137

19. Weeber KR, Shah MR, Sivasubramaniam K, El-Refaie A, Ronghai Q, et al. 2010. Advanced permanent magnet machines for a wide range of industrial applications. Power Energy Soc. Gen. Meet., IEEE, Minneapolis, MN, July 25-29, pp. 1-6

20. Skomski R. 2008. Simple Models of Magnetism. Oxford, UK: Oxford Univ. Press

21. Kumar K. 1988. RETM 5 and RE RM $_{17}$ permanent magnets development. F. Appl. Pbys. 63:R13-57

22. Skomski R, Coey JMD. 1999. Permanent Magnetism. Bristol, UK: Inst. Phys.

23. Bloch F, Gentile G. 1931. Zur Anisotropie der Magnetisierung ferromagnetischer Einkristalle. Z. Phys. 70:395-408

24. Herbst JF. 1991. $\mathrm{R}_{2} \mathrm{Fe}_{14} \mathrm{~B}$ materials: intrinsic properties and technological aspects. Rev. Mod. Phys. 63:819_ 98

25. Manchanda P, Sahota PK, Skomski R, Kumar PSA, Kashyap A. 2011. First-principle description of magnonic $\mathrm{Pd}_{n} \mathrm{Fe}_{m}$ multilayers. F. Appl. Phys. 109:07C110

26. Oppeneer PM, Antonov VN, Kraft T, Eschrig H, Yaresko AN, Perlov AY. 1996. First-principles study of the giant magneto-optical Kerr effect in MnBi and related compounds. F. Appl. Phys. 80:1099-105

27. Mishima T. 1931. Magnet steel containing nickel and aluminium. Br. Patent No. 378,478 
28. Mishima T. 1932. Aciers magnétiques au nickel-aluminium. Fr. Patent No. FR731361 (A)

29. Mishima T. 1936. Magnet steel containing nickel and aluminium. US Patent No. 2,027,994 (A)

30. Buschow KHJ, de Boer FR. 2003. Physics of Magnetism and Magnetic Materials. New York: Springer

31. Katter M, Zapf L, Blank R, Fernengel W, Rodewald W. 2011. Corrosion mechanism of RE-Fe-Co-CuGa-Al-B magnets. IEEE Trans. Magn. 37:2474-76

32. Bala H, Trepak NM, Szymura S, Lukin AA, Gaudyn VA, et al. 2001. Corrosion protection of Nd-Fe-B type permanent magnets by zinc phosphate surface conversion coatings. Intermetallics 9:515-19

33. Parker RJ. 1990. Advances in Permanent Magnetism. New York: Wiley

34. Manchanda P, Kumar P, Kashyap A, Lucis MJ, Shield JE, et al. 2013. Intrinsic properties of Fe-substituted L1 $1_{0}$ magnets. IEEE Trans Magn. 49:5194-98

35. Zhao X, Nguyen MC, Zhang WY, Wang CZ, Kramer MJ, et al. 2014. Exploring the structural complexity of intermetallic compounds by an adaptive genetic algorithm. Phys. Rev. Lett. 112:045502

36. Hafner J, Wolverton C, Ceder G. 2006. Toward computational materials design: the impact of density functional theory on materials research. MRS Bull. 31:659-65

37. Nguyen MC, Zhao X, Ji M, Wang CZ, Harmon B, Ho KM. 2012. Atomic structure and magnetic properties of $\mathrm{Fe}_{1-x} \mathrm{Co}_{x}$ alloys. F. Appl. Phys. 111:07E338

38. Skomski R, Kashyap A, Enders A. 2011. Is the magnetic anisotropy proportional to the orbital moment? 7. Appl. Phys. 109:07E143

39. Belashchenko KD, Antropov VP, Zein ZE. 2006. Self-consistent local GW method: application to $3 d$ and $4 d$ metals. Phys. Rev. B 73:073105

40. Antropov VP, Schilfgaarde V, Brink S, Xu JL. 2006. On the calculation of exchange interactions in metals. 7. Appl. Phys. 99:08F507

41. Medvedeva NI, Van Aken D, Medvedeva JE. 2010. Magnetism in bcc and fcc Fe with carbon and manganese. 7. Phys. Condens. Matter 22:316002

42. Rahman G, Kim IG, Bhadeshia HKDH, Freeman AJ. 2010. First-principles investigation of magnetism and electronic structures of substitutional $3 d$ transition-metal impurities in bcc Fe. Phys. Rev. B 81:184423

43. Kogachi M, Tadachi N, Kohata H, Ishibashi H. 2005. Magnetism and point defect in B2-type CoFe alloys. Intermetallics 13:535-42

44. Kashyap A, Manchanda P, Sahota PK, Skomski R, Shield JE, Sellmyer DJ. 2011. Anisotropy of W in Fe and Co. IEEE Trans. Magn. 47:3336-39

45. Sharma V, Manchanda P, Skomski R, Sellmyer DJ, Kashyap A. 2011. Anisotropy of heavy transition metal dopants in Co. F. Appl. Phys. 109:07A727

46. Skomski R, Sharma V, Balamurugan B, Shield JE, Kashyap A, Sellmyer DJ. 2010. Anisotropy of doped transition-metal magnets. REPM'10 Proc. 21st Workshop Rare-Earth Perm. Magn. Appl., Bled, Slov., pp. 5560. Ljubljana, Slov.: Jožef Stefan Inst.

47. Cahn JW. 1963. Magnetic aging of spinodal alloys. 7. Appl. Phys. 34:3581-86

48. Marin P, Hernando A. 2009. Enhanced magnetic properties of FeCo ribbons nanocrystallized in magnetic field. Appl. Phys. Lett. 94:122507

49. Mendelsohn LI, Luborsky FE, Paine TO. 1955. Permanent-magnet properties of elongated single-domain iron particles. F. Appl. Phys. 26:1274-80

50. Luborsky FE, Mendelsohn LI, Paine TO. 1957. Reproducing the properties of alnico permanent magnet alloys with elongated single-domain cobalt-iron particles. F. Appl. Phys. 28:344-50

51. Campbell RB, Julien CA. 1961. Structure of alnico V. F. Appl. Phys. 32:S192

52. Julien CA, Jones FG. 1965. Alpha-sub-gamma phase in alnico 8 alloys. F. Appl. Phys. 36:1173

53. Zeng H, Skomski R, Menon L, Liu LY, Bandyopadhyay S, Sellmyer DJ. 2002. Structure and magnetic properties of ferromagnetic nanowires in self-assembled arrays. Phys. Rev. B 65:134426

54. Zhou L, Miller MK, Dillon H, Palasyuk A, Constantinides S, et al. 2014. Role of the applied magnetic field on the microstructural evolution in alnico 8 alloys. Metall. Mater. Trans. E 1(1):27-35

55. Went JJ, Rathenau GW, Gorter EW, Oosterhout V. 1952. Hexagonal iron oxide compounds as permanent-magnet materials. Phys. Rev. 86:424-25

56. Goodenough JB. 1958. An interpretation of the magnetic properties of the perovskite-type mixed crystals $\mathrm{La}_{1-x} \mathrm{Sr}_{x} \mathrm{CoO}_{3-\lambda}$. F. Phys. Chem. Solids 6:287-97 
57. Stuijts AL, Rathenau GW, Weber GH. 1954. Ferroxdure II and III, anisotropic permanent-magnet materials. Philips Tech. Rev. 16:141-47

58. Scott ERD, Clark RS Jr. 1980. Ordering of FeNi in clear taenite from meteorites. Nature 287:255

59. Lewis LH, Mubarok A, Poirier E, Bordeaux N, Manchanda P, et al. 2014. Inspired by nature: investigating tetrataenite for permanent magnet applications. F. Phys. Condens. Mat. 26:064213

60. Coey JMD, Smith PAI. 1999. Magnetic nitrides. 7. Magn. Magn. Mater. 200:405-24

61. Ji N, Osofsky MS, Lauter V, Allard LF, Li X, et al. 2011. Perpendicular magnetic anisotropy and high spin polarization ratio in epitaxial Fe-N thin films. Phys. Rev. B 84:245310

62. Ji N, Allard LF, Lara-Curzio E, Wang JP. 2011. N site ordering effect on partially ordered $\mathrm{Fe}_{16} \mathrm{~N}_{2}$. Appl. Phys. Lett. 98:092506

63. Hadjipanayis GC, Liu JF, Gabay A, Marinescu M. 2006. Current status of rare-earth permanent magnet research in USA. 7. Iron Steel Res. Int. 13:12-22

64. Huang MQ, Wallace WE, Simizu S, Sankar SG. 1994. Magnetism of $\alpha^{\prime \prime}-\mathrm{FeN}$ alloys and $\alpha^{\prime \prime}-\left(\mathrm{Fe}_{16} \mathrm{~N}_{2}\right)$ Fe nitrides. 7. Magn. Magn. Mater. 135:226-30

65. Ogawa T, Ogata Y, Gallage R, Kobayashi N, Hayashi N, et al. 2013. Challenge to the synthesis of $\alpha^{\prime \prime}-$ $\mathrm{Fe}_{16} \mathrm{~N}_{2}$ compound nanoparticle with high saturation magnetization for rare earth free new permanent magnetic material. Appl. Phys. Express 6:073007

66. Yamamoto S, Gallage R, Ogata Y, Kusanod Y, Kobayashibe N, et al. 2013. Quantitative understanding of thermal stability of $\alpha^{\prime \prime}-\mathrm{Fe}_{16} \mathrm{~N}_{2}$. Chem. Commun. 49:7708-10

67. Jack KH. 1951. Electronic band structure and magnetism of $\mathrm{Fe}_{16} \mathrm{~N}_{2}$ calculated by the FLAPW method. Proc. R. Soc. A 208:200-16

68. Jack KH. 1951. The occurrence and the crystal structure of $\alpha^{\prime \prime}$ iron nitride; a new type of interstitial alloy formed during the tempering of nitrogen-martensite. Proc. R. Soc. A 208:216-24

69. Kooi BJ, Somers MAJ, Mittemeijer EJ. 1996. Development of compound layer during nitriding and nitrocarburizing — current understanding and future challenges. Metall. Mater. Trans. A 27:1063-71

70. Jack KH. 2000. $\alpha^{\prime \prime} \mathrm{Fe}_{16} \mathrm{~N}_{2}$ : a giant magnetic moment material? Mater. Sci. Forum 325-26:91-98

71. Ohtani T, Kato N, Kojima S, Kojima K, Sakamoto Y, et al. 1977. Magnetic properties of Mn-Al-C permanent magnet alloys. IEEE Trans. Magn. 13:1328-30

72. Yang JB, Kamaraju K, Yelon WB, James WJ, Cai Q, Bollero A. 2001. Magnetic properties of the MnBi intermetallic compound. Appl. Phys. Lett. 79:1846-48

73. ASM Int. 2006. Bismuth manganese binary diagram. Alloy Phase Diagram Database, Materials Park, OH, updated 2014. http://www1.asminternational.org/AsmEnterprise/APD

74. Andresen AF, Hälg W, Fischer P, Stoll E. 1967. Magnetic and crystallographic properties of MnBi studied by neutron diffraction. Acta Chem. Scand. 21:1543-54

75. Mikio K, Kunio W. 1975. Temperature dependence of coercivity of manganese-bismuth (MnBi) particles. 7pn. 7. Appl. Phys. 14:893-94

76. Yang JB, Chen XG, Guo S, Yan AR, Huang QZ, et al. 2013. Temperature dependences of structure and coercivity for melt-spun MnBi compound. F. Magn. Mater. 330:106-10

77. Guo X, Chen X, Altounian Z, Stromolsen JO. 1992. Magnetic properties of MnBi prepared by rapid solidification. Phys. Rev. B 46:14578-82

78. Rao NVR, Gabay AM, Hadjipanayis GC. 2013. Anisotropic fully dense MnBi permanent magnet with high energy product and high coercivity at elevated temperatures. 7. Phys. D Appl. Phys. 46:062001

79. Zhang DT, Cao S, Yue M, Liu WQ, Zhang JX, Qiang Y. 2011. Structural and magnetic properties of bulk MnBi permanent magnets. F. Appl. Phys. 109:07A722

80. Kim YJ, Perepezko JH. 1993. The thermodynamics and competitive kinetics of metastable $\tau$ phase development in MnAl-base alloys. Mater. Sci. Eng. A 163:127-34

81. Campbell RB, Julien CA. 1961. Ferromagnetic phase of Mn-Al. F. Appl. Phys. 32:S346

82. Abdelnour ZA, Mildrum HF, Strnat KJ. 1981. Permanent magnet properties of $\mathrm{Mn}$-Al-C between $-50^{\circ} \mathrm{C}$ and $+150^{\circ} \mathrm{C}$. IEEE Trans. Magn. 17:2651-53

83. Zeng Q, Baker I, Cui JB, Yan ZC. 2007. Structural and magnetic properties of nanostructured Mn-Al-C magnetic materials. F. Magn. Magn. Mater. 308:214-26

84. Müller C, Stadelmaier HH, Reinsch B, Petzow G. 1997. Constitution of Mn-Al-(Cu, Fe, Ni or C) alloys near the magnetic $\tau$ phase. Z. Metall. 88:620-24 
85. Pareti L, Bolzoni F, Leccabue F, Ermakov AE. 1986. Magnetic anisotropy of MnAl and MnAlC permanent magnet materials. 7. Appl. Phys. 59:3824-28

86. McCurrie RA, Rickman J, Dunk P, Hawkridge DG. 1978. Dependence of the permanent magnet properties of $\mathrm{Mn}_{55} \mathrm{Al}_{45}$ on particle size. IEEE Trans. Magn. 14:682-84

87. Fazakas E, Varga LK, Mazaleyrat F. 2007. Preparation of nanocrystalline Mn-Al-C magnets by melt spinning and subsequent heat treatments. F. Alloys Compd. 434-35:611-13

88. Park JH, Hong YK, Bae S, Lee JJ, Jalli J, et al. 2010. Saturation magnetization and crystalline anisotropy calculations for $\mathrm{MnAl}$ permanent magnet. 7. Appl. Phys. 107:09A731

89. Zeng Q, Baker I, Yan Z. 2006. Nanostructured Mn-Al permanent magnets produced by mechanical milling. F. Appl. Phys. 99:08E902

90. Du Y, Wang J, Zhao JR, Schuster JC, Weitzer F, et al. 2007. Reassessment of the Al-Mn system and a thermodynamic description of the Al-Mg-Mn system. Int. F. Mater. Res. 98:855-71

91. Li XZ, Kharel P, Shah VR, Sellmyer DJ. 2011. Synthesis and characterization of highly textured Pt-Bi thin films. Philos. Mag. 91:3406-15

92. Kharel P, Skomski R, Sellmyer DJ. 2011. Spin correlations and electron transport in MnBi:Au films. 7. Appl. Phys. 109:07B709

93. Yang JB, Yelon WB, James WJ, Cai Q, Kornecki M, et al. 2002. Crystal structure, magnetic properties and electronic structure of the MnBi intermetallic compound. F. Phys. Condens. Matter 14:6509-19

94. Kneller EF, Hawig R. 1991. The exchange-spring magnet: a new material principle for permanent magnets. IEEE Trans. Magn. 27:3588-600

95. Haxel GB, Hedrick JB, Orris GJ. 2002. Rare earth elements-critical resources for bigh technology. Fact Sheet 087-02, US Geol. Surv., Washington, DC

96. Sinnema S, Radwanski RJ, Franse JJM, de Mooij DB, Buschow KHJ. 1984. Magnetic properties of ternary rare-earth compounds of the type $\mathrm{R}_{2} \mathrm{Fe}_{14}$ B. 7. Magn. Magn. Mater. 44:333-41

97. Janssen Y, Chang S, Kreyssig A, Kracher A, Mozharivskyj Y, et al. 2007. Magnetic phase diagram of $\mathrm{Ce}_{2} \mathrm{Fe}_{17}$. Phys. Rev. B 76:054420

98. Strnat K, Hoffer G, Ostertag W, Olson JC. 1966. Ferrimagnetism of the rare-earth-cobalt intermetallic compounds $\mathrm{R}_{2} \mathrm{Co}_{17}$.7. Appl. Phys. 37:1252-53

99. Cherry LV, Wallace WE. 1962. Magnetic studies of some intermetallic compounds between cobalt and the lanthanide elements. F. Appl. Phys. 33:1515-17 